\title{
¿Impact of Developing ENSO on Tibetan Plateau Summer Rainfall
}

\author{
ShUAi Hu, ${ }^{\mathrm{a}, \mathrm{b}}$ TIANJUN ZHOU, ${ }^{\mathrm{a}, \mathrm{b}, \mathrm{c}}$ AND Bo Wu ${ }^{\mathrm{a}, \mathrm{c}}$ \\ a State Key Laboratory of Numerical Modeling for Atmospheric Sciences and Geophysical Fluid Dynamics, \\ Institute of Atmospheric Physics, Chinese Academy of Sciences, Beijing, China \\ ${ }^{\mathrm{b}}$ University of the Chinese Academy of Sciences, Beijing, China \\ ${ }^{\mathrm{c}}$ CAS Center for Excellence in Tibetan Plateau Earth Sciences, Chinese Academy of Sciences, Beijing, China
}

(Manuscript received 10 August 2020, in final form 23 December 2020)

\begin{abstract}
The year-to-year variations of Tibetan Plateau (TP) summer rainfall have tremendous climate impacts on the adjoining and even global climate, attracting extensive research attention in recent decades to understand the underlying mechanism. In this study, we investigate an open question of how El Niño-Southern Oscillation (ENSO) influences the TP precipitation. We show that the developing ENSO has significant impacts on the summer rainfall over the southwestern TP (SWTP), which is the second EOF mode of the interannual variability of summer rainfall over the TP. The moisture budget indicates that both the suppressed vertical motion and the deficit of moisture contribute to the reduction of SWTP rainfall during El Niño's developing summer, with the former contribution 4 times larger than the latter. Moist static energy analyses indicate that the anomalous advection of climatological moist enthalpy by anomalous zonal wind is responsible for the anomalous descending motions over the SWTP. The El Niño-related southward displacements of the South Asian high and the upper-level cyclonic anomalies over the west of TP stimulated by the suppressed Indian summer monsoon precipitation are two key processes dominating the anomalous zonal moist enthalpy advection over SWTP. Meanwhile, the India-Burma monsoon trough is strengthened during El Niño developing summer, which prevents the advection of water vapor into the SWTP, and thus contributes to the deficit of summer SWTP rainfall. Our results help to understand the complicated ENSO-related air-sea interaction responsible for the variability of TP precipitation and have implications for seasonal prediction of the TP climate.
\end{abstract}

KEYWORDS: El Niño; ENSO; Climate variability; Interannual variability; Precipitation

\section{Introduction}

The Tibetan Plateau (TP), known as the "third pole" or "roof of the world," has substantial impacts on downstream ecosystems in the context of its function as the "Asian water tower" (Xu et al. 2008; Son et al. 2020), supplying water resources to more than a quarter of the world's population. The hydroclimate processes in the TP feed 10 great rivers including the Yangtze, Indus, Mekong, and Ganges Rivers, and thus significantly affect water availability and food security in the surrounding regions (Immerzeel et al. 2010). One of the most important factors modifying the TP hydroclimate is precipitation (Zhang et al. 2013). The TP rainfall mainly occurs in summer, accounting for more than $55 \%$ of the annual precipitation (Feng and Zhou 2012). The abnormal condensation latent heating associated with the precipitation anomalies can modulate the atmospheric heat source over the TP in summer (Duan and Wu 2008; Wu et al. 2012; Jiang et al. 2016), which can further drive the large-scale circulation and affect the climate of the Asian summer monsoon regions (Wu et al. 2007; Duan and $\mathrm{Wu}$ 2008; Wu et al. 2012; Hu and Duan 2015; Z. B. Wang et al. 2018; He et al. 2019). Therefore, understanding the mechanism of precipitation variability over the TP is of crucial importance to the climate community in Asian countries.

\footnotetext{
Denotes content that is immediately available upon publication as open access.

Corresponding author: Prof. Tianjun Zhou, zhoutj@lasg.iap. ac.cn
}

Many efforts have been devoted to the study of interannual variability of summer TP rainfall and suggested mechanisms include the summer North Atlantic Oscillation (NAO) (Liu and Yin 2001; Liu et al. 2015; Z. Q. Wang et al. 2017, 2018), the Eurasian snow cover (Xu and Lu. 1992), the sea surface temperature (SST) in the Atlantic Ocean (Gao et al. 2013) and the Indian Ocean (Chen and You 2017), convection over the western Maritime Continent (Jiang et al. 2016), and the variability of the Indian summer monsoon (ISM) (Jiang and Ting 2017). As the dominant mode of interannual variability in the climate system, El Niño-Southern Oscillation (ENSO) exhibits notable impacts on global climate through atmospheric and oceanic teleconnections (Wang et al. 2000; Wu et al. 2017a,b; Yeh et al. 2018; Wang 2019). Previous studies on the impact of ENSO on TP summer precipitation have mostly focused on the decaying phase of ENSO. Two mechanisms are suggested. The first is related to the Indo-western Pacific ocean capacitor (Xie et al. 2016), which contains two key elements: the Indian Ocean basin mode (IOBM) (Klein et al. 1999) and the western North Pacific anomalous anticyclone (WNPAC) (Li et al. 2017). Driven by ENSO remote forcing and local air-sea interactions, the IOBM forms in ENSO mature winter, peaks in the following spring, and persists through summer (Klein et al. 1999). In El Niño's decaying spring, the positive phase of the IOBM characterized by SST warming in the tropical southwest Indian Ocean (SWIO) weakens the land-sea thermal contrast between the Eurasian continent and the Indian Ocean (Chen and You 2017). Meanwhile, the SST warming in the SWIO can be sustained by a downwelling Rossby wave forced by ENSO, which further produces an antisymmetric pattern of atmospheric anomalies in the tropical north Indian Ocean during spring and early summer (Xie 
et al. 2009; Du et al. 2009). Both the weakened land-sea thermal contrast and the antisymmetric circulation anomalies favor the delayed outbreak of the South Asian summer monsoon, and reduce the precipitation over the southeastern TP in May (Chen and You 2017). At the same time, the SWIO's warming can stimulate an abnormal local Hadley circulation in the northeast-to-southwest direction, with its subsiding branch located at the southeastern TP, which causes divergence of water vapor and also helps to reduce the TP precipitation in May (Zhao et al. 2018). After the onset of the summer monsoon, the antisymmetric circulation anomalies associated with the SWIO's warming force a second SST warming in the tropical north Indian Ocean. The persistent SST warming over the tropical north Indian Ocean helps to maintain the WNPAC through the Indian Ocean capacitor mechanism during El Niño's decaying summer (Xie et al. 2009; B. Wu et al. 2009, 2010). The circulation anomalies associated with the intensification and westward extension of WNPAC lead to more water vapor into the southeastern TP and thus increase the precipitation in summer (Ren et al. 2017).

The second mechanism of ENSO's delayed impact on TP summer precipitation is through the NAO. ENSO can induce an NAO-like circulation anomalies in North Atlantic and western Europe during boreal winter, with a negative (positive) NAO sign for El Niño (La Niña) (Moron and Gouirand 2003; Zhang et al. 2019). The NAO signals are relatively confined to the Euro-Atlantic sector in December whereas they extend toward East Asia and the North Pacific in February on the interannual time scale (Watanabe 2004). The anomalous NAO in spring (April-May) can induce a tripole SST pattern in the North Atlantic ( $\mathrm{Z}$. Wu et al. 2009). Although sometimes a strong SST tendency over the North Atlantic has been observed from spring and summer (Kim et al. 2017), the tripole SST pattern can generally persist into the following summer (Park et al. 2015) and excite downstream development of subpolar teleconnections across northern Eurasia, affecting the East Asian summer climate (Z. Wu et al. 2009). Nevertheless, the simultaneous correlations between ENSO and the NAO in the summertime are weaker than their counterparts in winter (Folland et al. 2009; Knight et al. 2009), although the summer NAO is active in modulating the TP precipitation (Liu and Yin 2001; Liu et al. 2015; Z. Q. Wang et al. 2017, 2018).

In comparison to the studies on the ENSO-TP precipitation relationship in El Niño decaying summers, less attention has been paid to the El Niño developing year (Wang and Ma 2018). One early observational analysis found that most droughts in the TP occurred in El Niño years, whereas severe floods in the central TP tended to occur in La Niña years (Pubu et al. 2002). The summer precipitation over the TP was shown to have a significant quasi-3-yr cycle, which was closely related with the simultaneous SST anomalies (SSTA) over the tropical central to eastern Pacific, with the developing eastern Pacific-type El Niño (the developing eastern Pacific La Niña and the decaying of the central Pacific La Niña) accompanied by a decrease (increase) in the summer TP rainfall, respectively (Wang and Ma 2018). The developing phase of El Niño can give rise to an excessive snow cover over the western TP in spring, which is associated with the negative diabatic heating in the western North Pacific and Maritime Continent (Jin et al. 2017). The simultaneous ENSO signal was also detected in the stable isotopes of precipitation and ice cores over the TP (Yang et al. 2000; Gao et al. 2018; Yang et al. 2018). A recent study of the TP hydrologic climate suggests that significant lake shrinkage occurred on the central TP (CTP) due to a dramatic decrease in precipitation during the El Niño developing summer (Lei et al. 2019). These results suggest that the developing phase of ENSO can exert impacts on the TP summer climate. However, the mechanisms of how developing ENSO events influence the TP precipitation remain unknown. In this study, we aim to answer the following questions: 1) How does ENSO affect the interannual variability of summer rainfall over the TP during its developing phase? 2) Which regions of the TP are more sensitive to ENSO forcing?

The remainder of the paper is organized as follows. A description of datasets and analytical methods is given in section 2. In section 3 , we show the response of TP summer rainfall to the ENSO in the observations, and reveal the possible physical mechanisms. Finally, the conclusions and discussion are given in section 4 .

\section{Data and methods}

\section{a. Datasets}

The following observational and reanalysis datasets are used in this study: 1) the precipitation data from the Asian PrecipitationHighly Resolved Observational Data Integration toward Evaluation of Water Resources (APHRODITE; Yatagai et al. 2012); 2) the precipitation data from the Global Precipitation Climatology Project (GPCP; Adler et al. 2003); 3) the monthly mean atmospheric circulation data from the European Centre for Medium-Range Weather Forecasts reanalysis (ERA5; Hersbach and Dee 2016); 4) the monthly mean SST data from the Met Office Hadley Centre Sea Ice and SST dataset (HadISST version 1.1; Rayner et al. 2003); and 5) the monthly sea level pressure data from the Hadley Centre Sea Level Pressure dataset (HadSLP2; Ansell and Allan 2006). All the datasets are monthly mean and cover the period 1979-2017, except for APHRODITE, which only covers the period 1979-2015.

\section{b. Method}

Following the definition of Folland et al. (2009), the summer NAO (SNAO) index is defined as the first principal component time series corresponding to the first empirical orthogonal function (EOF) mode of the summer mean sea level pressure anomalies over $25^{\circ}-70^{\circ} \mathrm{N}, 70^{\circ} \mathrm{W}-50^{\circ} \mathrm{E}$. The EOF analysis over this region mainly reproduces the southern node of the full SNAO pattern (Z. Q. Wang et al. 2018), and thus the SNAO index is positive (negative) when the sea level pressure over the southern node of SNAO is higher (lower) than average pressure. The monthly Niño-3.4 index is defined as the area-averaged SSTAs in the equatorial central and eastern Pacific $\left(5^{\circ} \mathrm{S}-5^{\circ} \mathrm{N}, 170^{\circ}-120^{\circ} \mathrm{W}\right)$. To focus on the interannual variability, the 9-yr high-pass Lanczos filter is applied (Duchon 1979).

To understand the mechanisms responsible for the precipitation anomalies, the atmospheric moisture equation (Seager et al. 2010; Wu et al. 2017a,b) was diagnosed as follows:

$$
P^{\prime}=-\left\langle u \partial_{x} q\right\rangle^{\prime}-\left\langle v \partial_{y} q\right\rangle^{\prime}-\left\langle\omega \partial_{p} q\right\rangle^{\prime}+E^{\prime}+\text { res },
$$

where primes are the monthly anomaly and angle brackets denote the mass-weighted vertical integral through the entire 
(a) APHRO EOF1

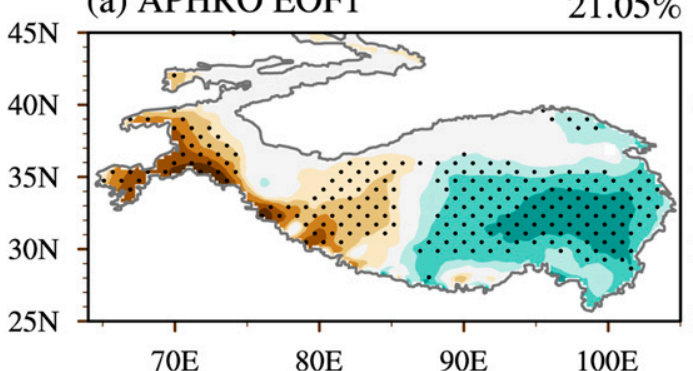

(c) GPCP EOF1

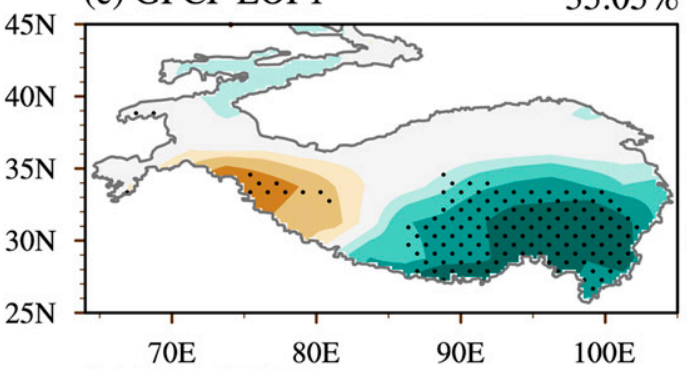

(b) APHRO EOF2

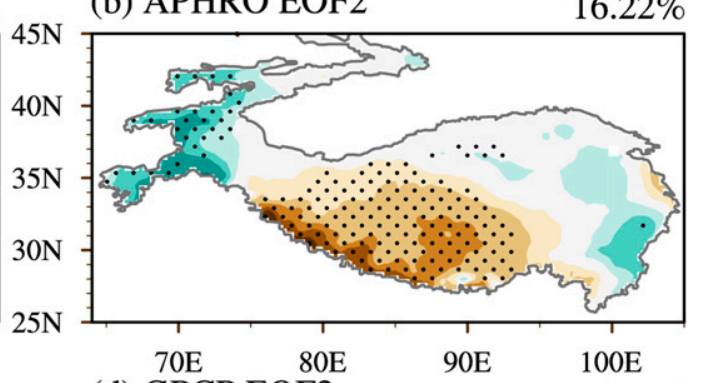

(d) GPCP EOF2

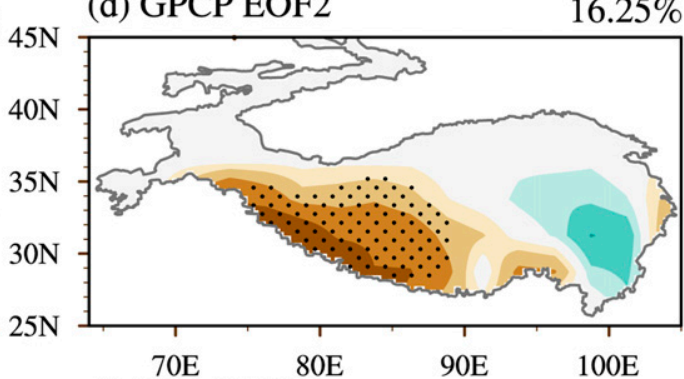

(e) ERA5 EOF1

$34.84 \%$

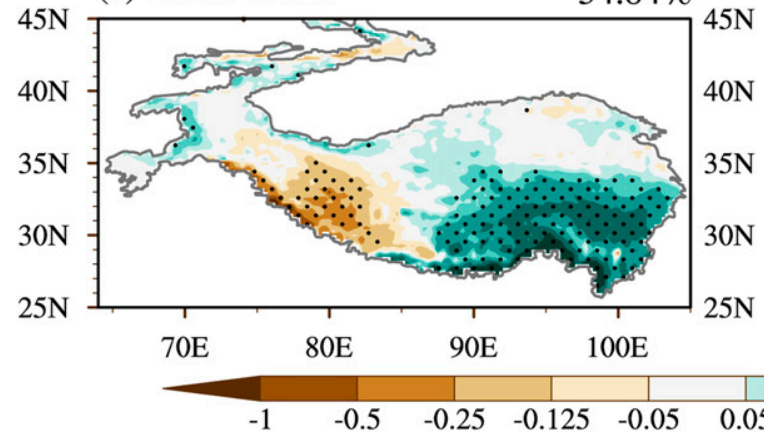

(f) ERA5 EOF2

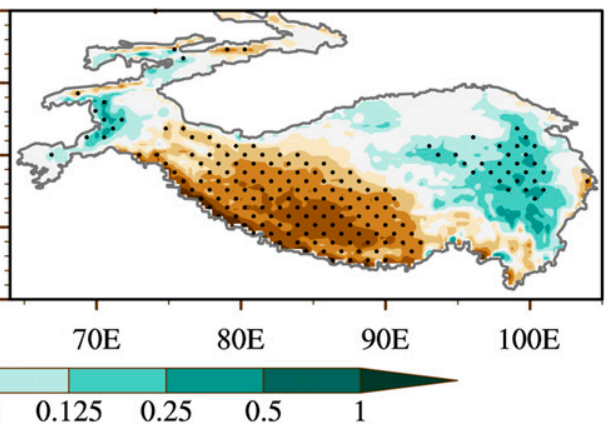

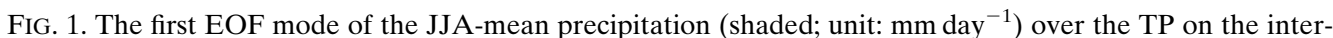
annual time scale derived from the (a) APHRODITE, (c) GPCP, and (e) ERA5. (b),(d),(f) As in (a), (c), and (e), but for the second EOF mode. Variance contributions of the two EOF modes are noted at the top right of each panel. The dots denote values exceeding the $95 \%$ confidence level. The TP is defined as the areas above the 2000-m elevation contour.

atmospheric column; $P$ and $E$ represent the precipitation and surface evaporation, respectively; $q$ denotes the specific humidity; $u, v$, and $\omega$ represent the horizontal (zonal and meridional) wind and vertical pressure velocity, respectively; $x, y$, and $p$ represent the zonal, meridional, and vertical direction, respectively; and "res" denotes the residual term.

The term $-\left\langle\omega \partial_{p} q\right\rangle^{\prime}$ can be decomposed into four terms as follows:

$$
-\left\langle\omega \partial_{p} q\right\rangle^{\prime}=-\left\langle\bar{\omega} \partial_{p} q^{\prime}\right\rangle-\left\langle\omega^{\prime} \partial_{p} \bar{q}\right\rangle-\left\langle\omega^{\prime} \partial_{p} q^{\prime}\right\rangle+\delta,
$$

where the two linear advection terms $-\left\langle\omega^{\prime} \partial_{p} \bar{q}\right\rangle$ and $-\left\langle\bar{\omega} \partial_{p} q^{\prime}\right\rangle$ denote the dynamic and thermodynamic processes of $-\left\langle\omega \partial_{p} q\right\rangle^{\prime}$, respectively (Seager et al. 2010). The term $-\left\langle\omega^{\prime} \partial_{p} q^{\prime}\right\rangle$ denotes the nonlinear advection; $\delta$ denotes the nonlinear submonthly transient term. We treat the sum of $-\left\langle\omega^{\prime} \partial_{p} q^{\prime}\right\rangle$ and $\delta$ as the nonlinear term (NL) in this study.

To investigate the mechanisms responsible for the anomalous vertical motion, the moist static energy (MSE) equation
(Neelin and Held 1987; Neelin 2007; Wu et al. 2017a,b) was diagnosed, which can be written as

$$
\begin{aligned}
\partial_{t}\left\langle C_{p} T+L_{v} q\right\rangle^{\prime} & +\left\langle u \partial_{x}\left(C_{p} T+L_{v} q\right)\right\rangle^{\prime}+\left\langle v \partial_{y}\left(C_{p} T+L_{v} q\right)\right\rangle^{\prime} \\
& +\left\langle\omega \partial_{p} h\right\rangle^{\prime}=F_{\text {net }}^{\prime},
\end{aligned}
$$

where $F_{\text {net }}$ represents the net flux into the atmospheric column. The term $h$ denotes the MSE, which can be written as $h=$ $C_{p} T+L_{v} q+\phi$. The term $\left(C_{p} T+L_{v} q\right)$ is the moist enthalpy; $C_{p}$ and $L_{v}$ are the specific heat at constant pressure and the latent heat of vaporization, respectively; $T$ denotes the air temperature; $q$ is the specific humidity; $\phi$ denotes the geopotential; $u, v$, and $\omega$ represent the horizontal (zonal and meridional) wind and vertical pressure velocity, respectively; and $x, y$, and $p$ represent the zonal, meridional, and vertical direction, respectively. The primes represent the monthly anomaly. The angle brackets denote the mass-weighted vertical integral through the entire atmospheric column. On the 
interannual time scale, the summer mean time tendency term $\left(\partial_{t}\left\langle C_{p} T+L_{v} q\right\rangle^{\prime}\right)$ is relatively smaller than other terms, and thus can be neglected.

The MSE equation can be simplified to

$$
\begin{aligned}
\left\langle\omega^{\prime} \partial_{p} \bar{h}\right\rangle \approx & F_{\text {net }}^{\prime}-\left\langle u^{\prime} \partial_{x} \overline{\left(C_{p} T+L_{v} q\right)}\right\rangle \\
& -\left\langle v^{\prime} \partial_{y} \overline{\left(C_{p} T+L_{v} q\right)}\right\rangle-\left\langle\bar{u} \partial_{x}\left(C_{p} T+L_{v} q\right)^{\prime}\right\rangle \\
& -\left\langle\bar{v} \partial_{y}\left(C_{p} T+L_{v} q\right)^{\prime}\right\rangle-\left\langle\bar{\omega} \partial_{p} h^{\prime}\right\rangle+\mathrm{NL},
\end{aligned}
$$

where NL is the nonlinear term. The primes (overbars) represent the monthly anomaly (climatology). In the tropical and subtropical monsoon region with deep convection, the gross moist stability is usually positive and the $\partial_{p} \bar{h}$ is usually less than 0 (Back and Bretherton 2006), and thus the negative terms on the right-hand side of Eq. (4) can drive anomalous descending motion under the constraints of the MSE budget balance.

The atmospheric precipitable water vapor $(\mathrm{PW})$ and the vertically integrated moisture flux $(Q)$ (Zhou and Yu 2005; Zhao and Zhou 2019; Zhou et al. 2019) are calculated as

$$
\begin{aligned}
\mathrm{PW} & =\frac{1}{g} \int_{100}^{p_{s}} q d p, \\
Q & =\frac{1}{g} \int_{100}^{p_{s}} q \mathbf{V} d p,
\end{aligned}
$$

where $q$ is specific humidity, $\mathbf{V}$ is horizontal wind vector, $p$ is pressure, $p_{s}$ is surface pressure, and $g$ is the acceleration due to gravity.

\section{Results}

\section{a. Observation analysis}

To identify the leading modes of interannual variability of TP precipitation during boreal summer [June-August (JJA)], an EOF analysis was performed to the 9-yr high-pass filtered JJA-mean precipitation anomalies over the entire TP, which is defined as the areas above the 2000-m elevation contour. To increase the reliability of our results, three different rainfall datasets were used, including the APHRODITE, GPCP, and ERA5. The three rainfall datasets show similar anomalous rainfall patterns of the first and second EOF modes, which account for $21.05 \%$ (16.22\%), 35.05\% (16.25\%), and $34.84 \%$ $(13.26 \%)$ of the total variance for APHRODITE, GPCP, and ERA5, respectively. According to North's criteria (North et al. 1982), the two EOF modes are significantly separated from each other. The first EOF mode is characterized by a dipolar pattern, with rainfall decreasing about $0.2 \mathrm{~mm}_{\text {day }}{ }^{-1}$ over the southwest TP and increasing about $0.5-1 \mathrm{~mm} \mathrm{day}^{-1}$ over the southeast TP (Figs. 1a,c,e). For the second EOF mode, the most significant anomalous center is located at the southwest TP, with a magnitude of $0.5-1 \mathrm{~mm}^{-1 a y}{ }^{-1}$ (Figs. $1 \mathrm{~b}, \mathrm{~d}, \mathrm{f}$ ).

The principal components (PCs) corresponding to the first two EOF modes are shown in Fig. 2. The first EOF mode is associated with the SNAO (Liu and Yin 2001; Liu et al. 2015; Z. Q. Wang et al. 2017, 2018), with the correlation coefficient reaching $-0.74,-0.54$, and -0.51 between the SNAO index (a) PC1 \& -SNAO index

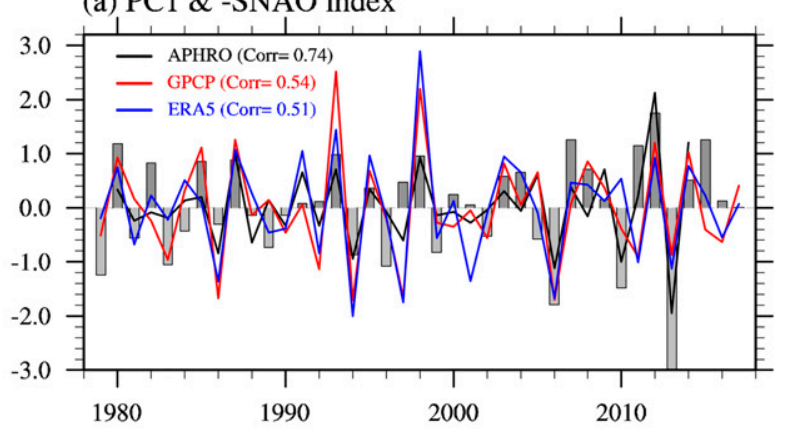

(b) PC2 \& Niño 3.4 index

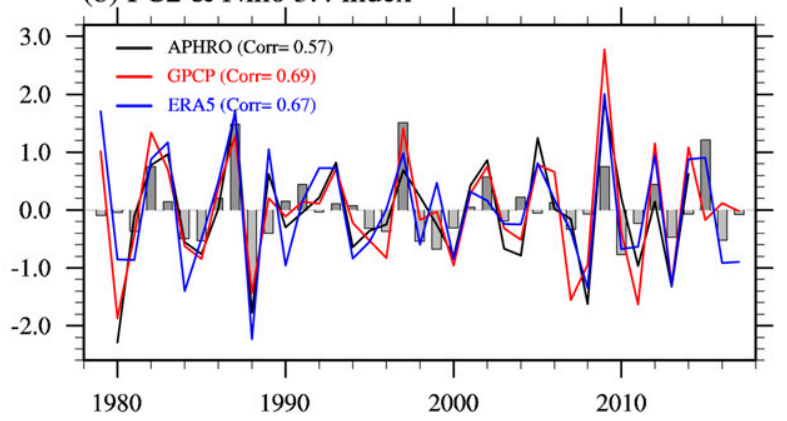

(c) Lead-lag correlations

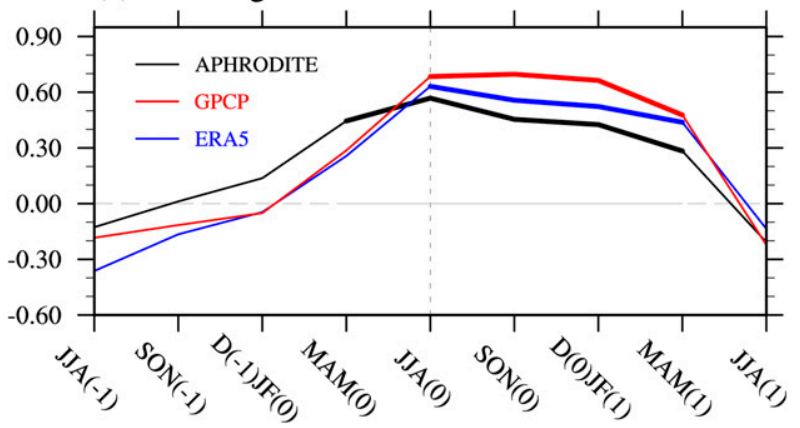

FIG. 2. (a) Time series of the normalized principal component corresponding to the first EOF mode (PC1) during 1979-2017 derived from APHRODITE (black line), GPCP (red line), and ERA5 (blue line). The normalized SNAO index is represented by the bars. (b) As in (a), but for the PC2 (lines) and the normalized concurrent summer Niño-3.4 index (bars). The correlation coefficients between the PC1 (PC2) and the SNAO index (Niño-3.4 index) are shown in parentheses in the legends. (c) Lead-lag correlation coefficients of the PC2 with the seasonal mean Niño3.4 index. The results of APHRODITE, GPCP, and ERA5 are shown by black, red, and blue lines, respectively. Numerals $-1,0$, and 1 denote the 1-yr lead, simultaneous year, and 1-yr lag, respectively. The thick line denotes values exceeding the $95 \%$ confidence level.

and the PC corresponding to the first EOF mode (PC1) for APHRODITE, GPCP, and ERA5, respectively (Fig. 2a). The second EOF mode is closely linked to the concurrent Niño-3.4 index. The correlation coefficients between the PC corresponding to the second EOF mode (PC2) and the concurrent Niño-3.4 index are 0.57, 0.69, and 0.67 for APHRODITE, GPCP, and ERA5, respectively (Fig. 2b). All the correlation 


\section{PC2}

(a) $\mathrm{D}(-1) \mathrm{JF}(0)$

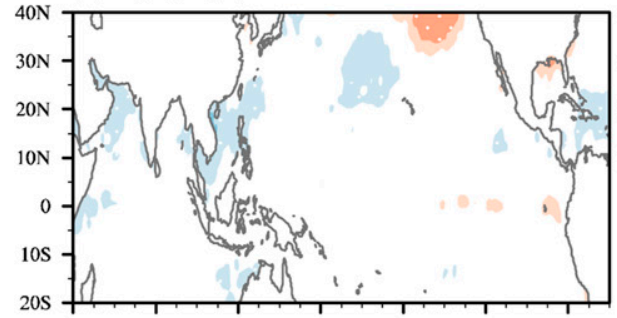

(b) $\operatorname{MAM}(0)$

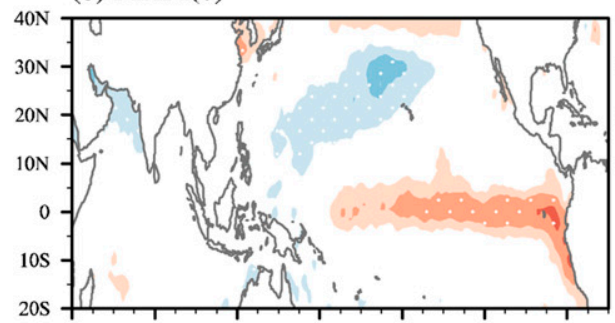

(c) $\mathrm{JJA}(0)$

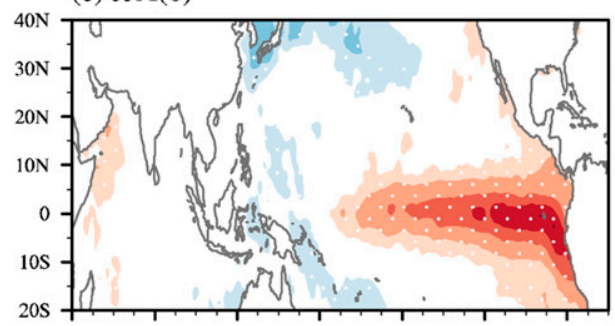

(d) $\operatorname{SON}(0)$

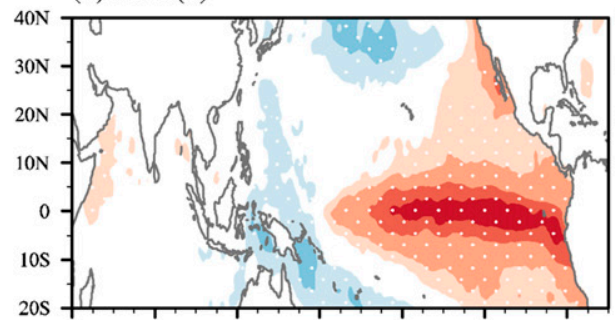

(e) $\mathrm{D}(0) \mathrm{JF}(1)$



Summer Niño 3.4

(f) $\mathrm{D}(-1) \mathrm{JF}(0)$

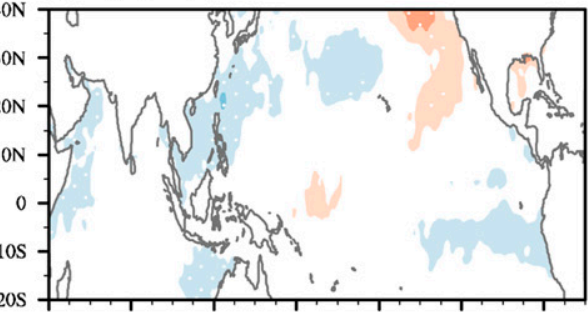

(g) $\operatorname{MAM}(0)$

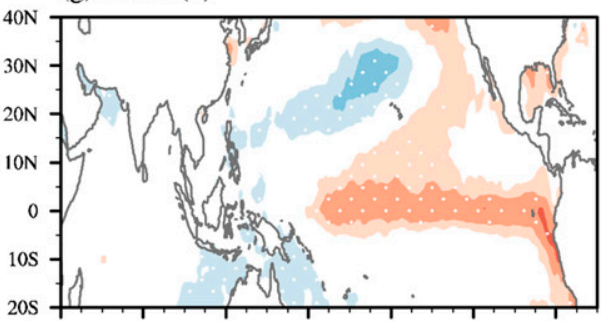

(h) $\mathrm{JJA}(0)$

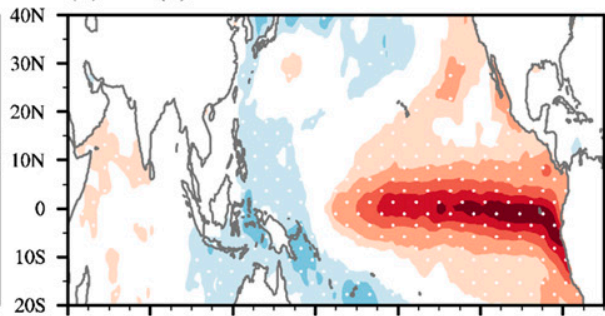

(i) $\mathrm{SON}(0)$



(j) $\mathrm{D}(0) \mathrm{JF}(1)$

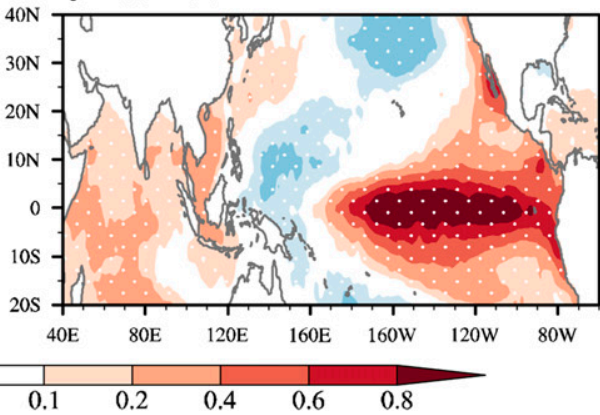

FIG. 3. Lead-lag regressions of seasonal mean SSTA onto the (a)-(e) PC2 and (f)-(j) summer mean $[\mathrm{JJA}(0)]$ Niño-3.4 index. (top to bottom) Seasonal mean SSTA is for $\mathrm{D}(-1) \mathrm{JF}(0), \operatorname{MAM}(0), \mathrm{JJA}(0)$, $\mathrm{SON}(0)$, and $\mathrm{D}(0) \mathrm{JF}(1)$, respectively. Numerals $-1,0$, and 1 denote the 1 -yr lead, simultaneous year, and 1 -yr lag. The dots denote values exceeding the $95 \%$ confidence level. 
(a) SSTA,Winds@200hPa,HGT@200hPa

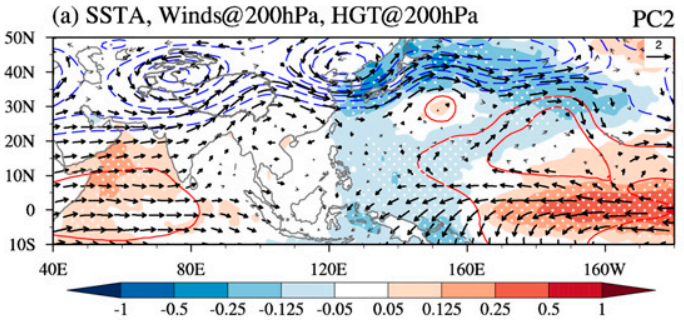

(b) Pr,Winds@850hPa

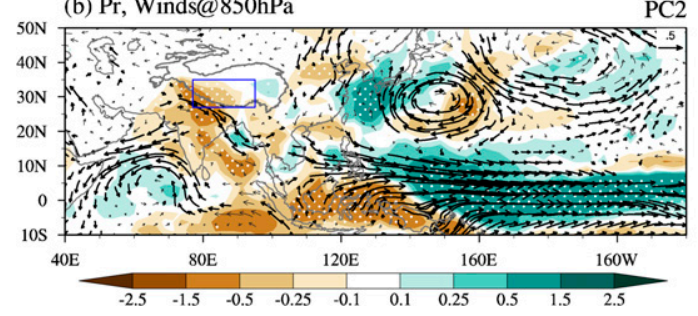

(c) SSTA,Winds@200hPa,HGT@200hPa

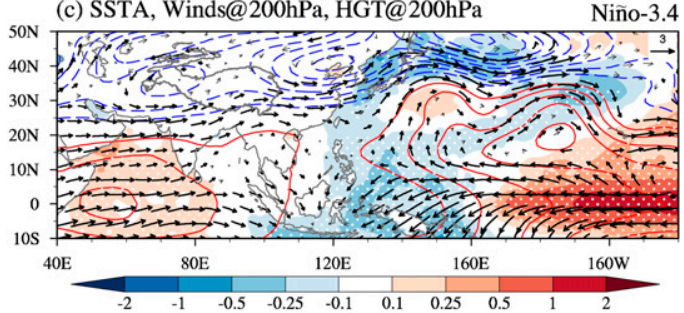

(d) Pr, Winds@850hPa

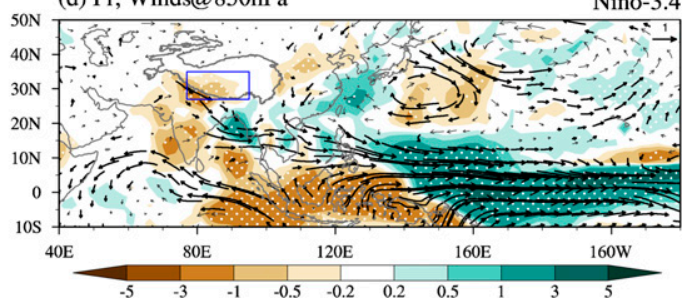

FIG. 4. (a) SST (shaded; unit: ${ }^{\circ} \mathrm{C}$ ), 200-hPa winds (vectors; unit: $\mathrm{m} \mathrm{s}^{-1}$ ), and 200-hPa geopotential anomalies [contours; unit: $\mathrm{m}^{2} \mathrm{~s}^{-2}$, interval: $30 \mathrm{~m}^{2} \mathrm{~s}^{-2}$; the positive (negative) values are shown in red solid (blue dashed) lines; zero contour is not shown] regressed onto the PC2 during the period of 1979-2017. (b) As in (a), but for the 850-hPa winds (vectors; unit: $\mathrm{m} \mathrm{s}^{-1}$ ) and precipitation anomalies (shaded; unit: $\mathrm{mm} \mathrm{day}^{-1}$ ) regressed onto PC2. (c),(d) As in (a) and (b), but for the regressions onto the summer Niño-3.4 index. The interval value of the 200-hPa geopotential anomalies is $40 \mathrm{~m}^{2} \mathrm{~s}^{-2}$. The observed SST comes from HadISST. The observed winds and geopotential are derived from ERA5, and the observed precipitation is from GPCP. The dots in all panels denote values exceeding the $95 \%$ confidence level. The thick vectors denote values exceeding the $90 \%$ confidence level. The gray terrain line is the 2000-m elevation contour. The blue box in (c) and (d) denotes the SWTP $\left(27^{\circ}-35^{\circ} \mathrm{N}, 77^{\circ}-95^{\circ} \mathrm{E}\right)$.

coefficients reach the $95 \%$ confidence level. The SNAOrelated first EOF mode has been demonstrated by previous studies (Liu and Yin 2001; Liu et al. 2015; Z. Q. Wang et al. 2017, 2018), and the detailed physical processes have been well revealed. For the influence of SNAO on summer TP rainfall, there are two suggested mechanisms (Wang et al. 2017). The first is associated with the weakened baroclinic vertical structure of atmospheric circulation over the TP caused by the convergence of wave-activity flux originating from northwestern Europe during positive SNAO events, which can suppress the pumping effect of TP and thus reduce the precipitation. The second is related to variations of the meridional position of the Asian jet stream driven by SNAO. During positive SNAO events, the northward movement of the jet stream can reduce the specific humidity and moisture transport at the western boundary of southern TP. In contrast, the mechanism for the second EOF mode (EOF2) remains unknown, and thus we mainly focus on the physical mechanism responsible for EOF2.

The lead-lag correlation coefficients between PC2 and the preceding (following) winter Niño-3.4 index are 0.137, 0.051, and $0.046(0.425,0.664$, and 0.522$)$ for APHRODITE, GPCP, and ERA5, respectively; see Fig. 2c. The PC2s have insignificant correlation coefficients with the antecedent winter Niño3.4 index, while the correlations with the following winter Niño-3.4 are statistically significant above the $95 \%$ confidence level. The lead-lag regressions of seasonal mean SSTA onto the $\mathrm{PC} 2$ suggest that the EOF2 of the summer TP rainfall may be connected with the developing ENSO (Figs. 3a-e). Although sometimes the summer Niño-3.4 index represents the slowly decaying of La Niña or slowly termination of El Niño, the lead- lag regressions of SSTA onto the summer Niño-3.4 index show a representative pattern of the developing ENSO (Figs. 3f-j). Hence, for simplicity of analysis, we take the concurrent summer Niño-3.4 index as the metric of the developing ENSO.

Based on the ERA5 dataset, the large-scale circulations associated with the EOF2 are shown in Figs. 4a and 4b. There are two anomalous cyclones located at the western TP and northeast China at $200 \mathrm{hPa}$, respectively, accompanied by $\mathrm{El}$ Niño-like positive SSTAs over the tropical central to eastern Pacific (Fig. 4a). At the 850-hPa level, there is an anomalous trough over the northern Bay of Bengal, with its center located at the south of the TP. Meanwhile, the negative precipitation anomalies are prevalent over the Indian subcontinent and the Maritime Continent, while positive precipitation anomalies cover the tropical central to the eastern Pacific (Fig. 4b). The regressions of the circulation and precipitation anomalies onto the concurrent summer Niño-3.4 are shown in Figs. 4c and 4d, whose spatial features are consistent with those of the PC2related anomalies, which further demonstrates the assumption that EOF2 may arise from the developing ENSO. So, how does the atmospheric circulation associated with the developing ENSO impact the TP precipitation? We will address this question in the next section.

\section{b. Physical mechanisms}

\section{1) Moisture BUdGeT ANALYSIS}

To investigate the detailed processes causing the precipitation anomalies over the TP associated with the developing ENSO, we applied the atmospheric moisture budget analysis 


\section{(a) JJA-mean SWTP Pr}

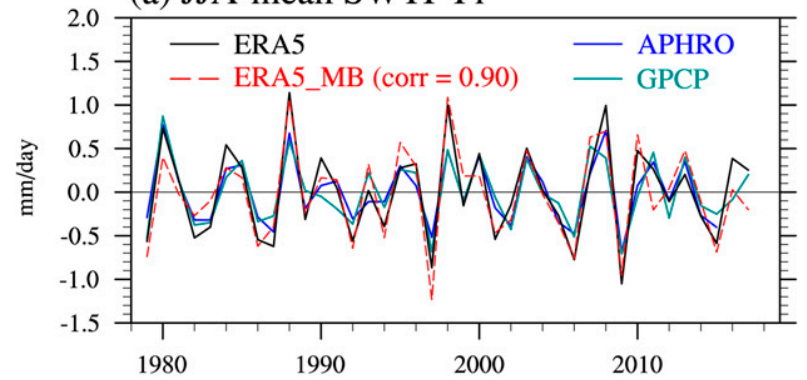

(b) Moisture budget

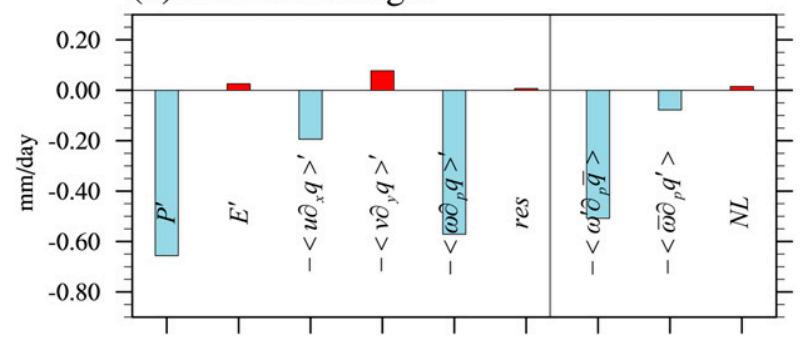

FIG. 5. (a) The sum of atmospheric moisture budget for the JJAmean precipitation anomalies over the SWTP $\left(27^{\circ}-35^{\circ} \mathrm{N}, 77^{\circ}-\right.$ $95^{\circ} \mathrm{E}$ ) (red dashed line) and the corresponding observed precipitation anomalies during 1979-2017. The observed precipitation anomalies from ERA5, APHRODITE, and GPCP are shown by black, blue, and green lines, respectively. The correlation coefficient between the sum of the moisture budget and the precipitation anomalies from ERA5 is shown in parentheses. (b) Budget analysis of the atmospheric moisture for the area SWTP. Each term is regressed against the summer Niño-3.4 index. Units are mm day ${ }^{-1}$.

for the area of southwest TP (SWTP: $27^{\circ}-35^{\circ} \mathrm{N}, 77^{\circ}-95^{\circ} \mathrm{E}$ ) based on the ERA5 dataset. The results show that the sum of the terms on the right side of the Eq. (1) is consistent with the observed variability of JJA-mean precipitation, with the correlation coefficient reaching 0.90 for ERA5 (Fig. 5a). The quantitative analysis of the negative precipitation anomalies over the SWTP associated with concurrent summer Niño-3.4 index is shown in Fig. 5b. The SWTP precipitation anomalies are mainly caused by the anomalous vertical advection of moisture $\left(-\left\langle\omega \partial_{p} q\right\rangle^{\prime}\right)$, while the evaporation and horizontal moisture advection have relatively small contributions.

The term $-\left\langle\omega \partial_{p} q\right\rangle^{\prime}$ can further be decomposed into two linear advection terms $\left(-\left\langle\bar{\omega} \partial_{p} q^{\prime}\right\rangle\right.$ and $\left.-\left\langle\omega^{\prime} \partial_{p} \bar{q}\right\rangle\right)$ and a nonlinear term (Fig. 5b). The results show that both the dynamic and thermodynamic processes of $-\left\langle\omega \partial_{p} q\right\rangle^{\prime}$ contribute to the reduction of SWTP precipitation, with the contribution of the dynamic processes being 4 times larger than that of the thermodynamic processes, while the nonlinear term has little contribution. Hence, we focus on the respective impacts of the anomalous dynamic and thermodynamic processes associated with the developing ENSO on the variation of SWTP summer precipitations as follows.

\section{2) THE DYNAMIC PROCESSES}

The horizontal distributions of dynamic term $\left(-\left\langle\omega^{\prime} \partial_{p} \bar{q}\right\rangle\right)$ are shown in Fig. 6b. There are negative anomalies over the SWTP,

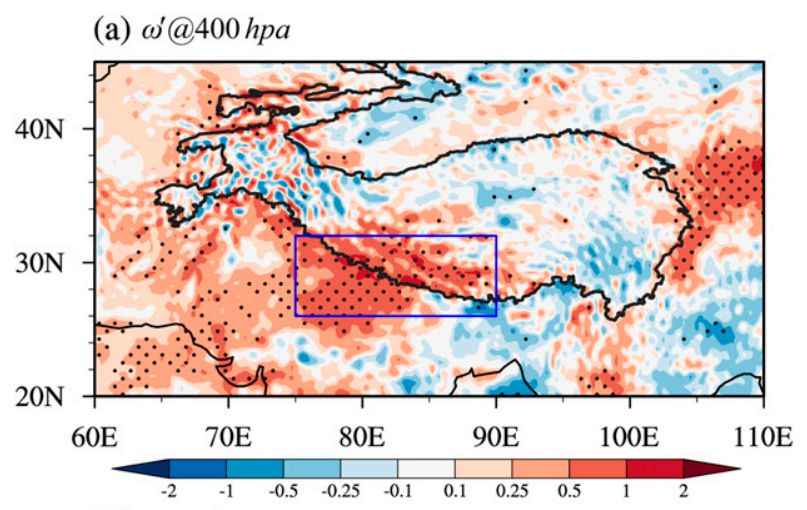

(b) $\left.-<\omega^{\prime} \partial_{p} \bar{q}\right\rangle$

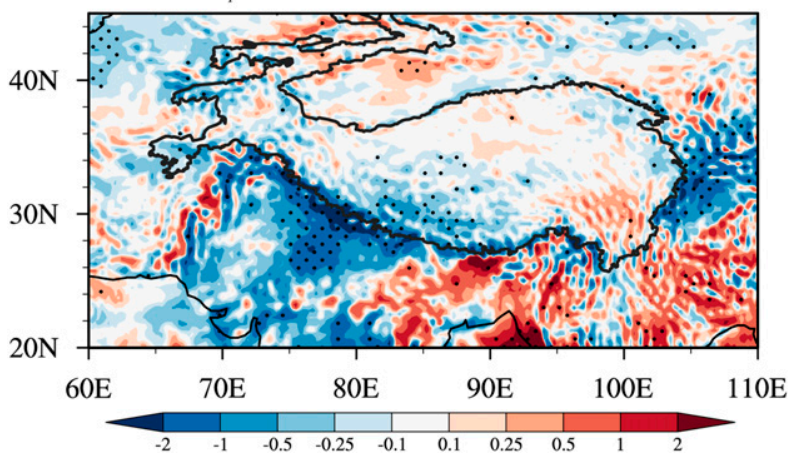

FIG. 6. (a) Spatial distribution of the regressions of JJA-mean 400-hPa vertical pressure velocity anomalies (shaded; multiplied by 80 ; unit: $\mathrm{Pa} \mathrm{s}^{-1}$ ) onto the summer Niño-3.4 index. (b) As in (a), but for the term $-\left\langle\omega^{\prime} \partial_{p} \bar{q}\right\rangle$ (shaded; unit: $\mathrm{mm} \mathrm{day}^{-1}$ ). The dots in both panels denote values exceeding the $95 \%$ confidence level. The gray terrain line is the $2000-\mathrm{m}$ elevation contour. The blue box in (a) is the positive center of the anomalous $400-\mathrm{hPa}$ atmospheric vertical flows.

with the central values about -1.0 to $-0.5 \mathrm{~mm} \mathrm{day}^{-1}$. The term $-\left\langle\omega^{\prime} \partial_{p} \bar{q}\right\rangle$ is mainly induced by the anomalous atmospheric vertical flows (Seager et al. 2012), whose vertical profiles over the SWTP show that the ENSO-related maximum anomalies emerge at the levels between 500 and $300 \mathrm{hPa}$ (figure not shown). The spatial distributions of ENSO-related vertical pressure velocity anomalies at $400 \mathrm{hPa}$ are shown in Fig. $6 \mathrm{a}$, which are highly consistent with the distributions of $-\left\langle\omega^{\prime} \partial_{p} \bar{q}\right\rangle$, indicating that the SWTP precipitation anomalies are mainly driven by the ENSO-related anomalous descending flows.

To understand the physical processes causing the anomalous descending motions over the SWTP during ENSO developing summer, we diagnosed the MSE equation [Eq. (4)] (Fig. 7). The results indicate that the anomalous advection of climatological moist enthalpy by anomalous horizontal winds has the largest contributions, which include $-\left\langle u^{\prime} \partial_{x} \overline{\left(C_{p} T+L_{v} q\right)}\right\rangle$ and $-\left\langle v^{\prime} \partial_{y} \overline{\left(C_{p} T+L_{v} q\right)}\right\rangle$, with the contribution of the former being twice as large as that of the latter. To investigate the detailed process of the anomalous horizontal moist enthalpy advection, a further decomposition is applied (Fig. 8). The results show that the anomalous zonal dry air advection $\left(-\left\langle u^{\prime} \partial_{x} \overline{\left(L_{v} q\right)}\right\rangle\right)$ has the largest contributions to the anomalous 


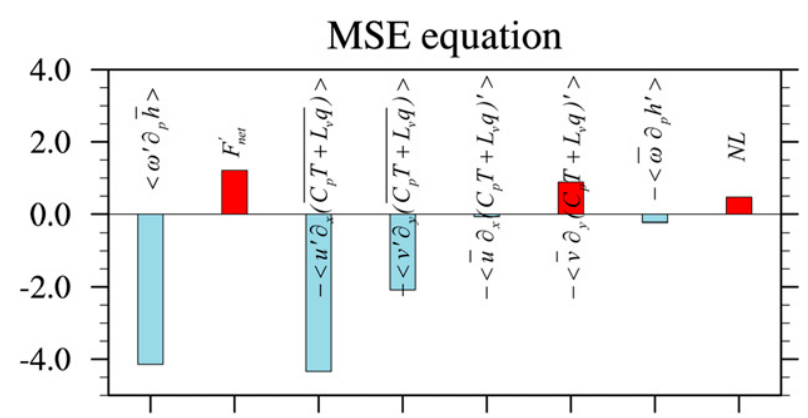

FIG. 7. Budget of the MSE equation for the positive center of the JJA-mean anomalous 400-hPa atmospheric vertical flows (see box in Fig. $5 \mathrm{a} ; 26^{\circ}-32^{\circ} \mathrm{N}, 75^{\circ}-90^{\circ} \mathrm{E}$ ). Each term is regressed against the summer Niño-3.4 index. Units are $\mathrm{W} \mathrm{m}^{-1}$.

zonal moist enthalpy advection over the SWTP (Fig. 8c). For the MSE budget equation [Eq. (4)], the term $-\left\langle u^{\prime} \partial_{x} \overline{\left(L_{v} q\right)}\right\rangle$ contributes to the reduced moist enthalpy coming into the atmospheric column, which can be balanced by vertical advection of mean MSE by the anomalous descending motion from the perspective of the energy balance. Therefore, the ENSOrelated anomalous zonal dry air advection is the dominant driver of the anomalous vertical flows over the SWTP.

To investigate the physical processes causing the anomalous zonal dry air advection, the vertical cross section of $-u^{\prime} \partial_{x} \overline{\left(L_{v} q\right)}$ along $30^{\circ} \mathrm{N}$ is shown in Fig. 9a. The results show that the developing ENSO can induce large negative zonal moist advection at the west edge of TP, which can be further intruded into the SWTP (Fig. 9a). The most pronounced negative $-u^{\prime} \partial_{x} \overline{\left(L_{v} q\right)}$ occurs at the 350 -hPa level over the SWTP, and thus we calculate the climatological specific humidity and the ENSO-related circulation anomalies at 350-hPa level (Fig. 9b). For the climatology, the atmospheric specific humidity gradually increases from northwest to southeast over the TP, supporting the TP as a "moist pool" in the middle-upper troposphere (Xu et al. 2008). For the anomalous circulations, there is an anomalous cyclone over the west of the TP at $350 \mathrm{hPa}$, with southwesterly anomalies dominating its southeastern flank (Fig. 9b). The westerly anomalies further advect dry air (low moist enthalpy) into the SWTP. According to the MSE equation, the negative anomalous moist enthalpy advection can induce the descending motions, and thus modulate the variability of precipitation over the SWTP. Hence, the ENSOrelated upper-level anomalous cyclonic circulations to the west of the TP and the westerly anomalies over the SWTP are the key systems influencing the SWTP precipitation.

How does the upper-level anomalous cyclone form during ENSO's developing summer? Previous studies found that two equivalent barotropic anticyclonic anomalies were occurring over the west of the TP and northeast China during the strong ISM years, which relate the ISM with the East Asian summer monsoon (EASM), referred to as the "ISM-EASM teleconnection" (Krishnan and Sugi 2001; Wang et al. 2001; Wu et al. 2003). The interannual variability of the ISM is simultaneously correlated with ENSO (Kumar 1999; Cherchi and Navarra 2012), with the weakened ISM occurring in El Niño years. The ISM precipitation anomalies are located close to the upperlevel westerly jet stream, and thus have strong impacts on the atmospheric teleconnection pattern (Ding and Wang 2005; Wang et al. 2012). To investigate the formation mechanism of the upper-level anomalous cyclone, the circulation anomalies (a)

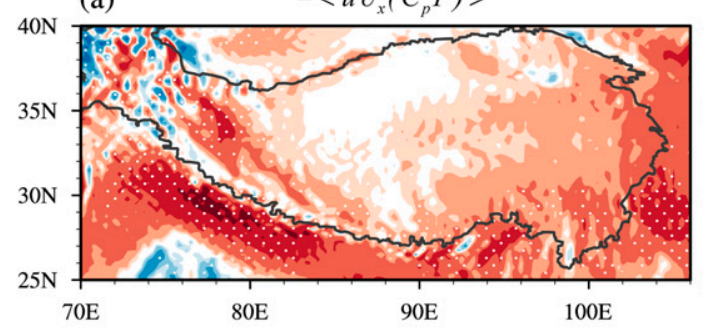

(c)

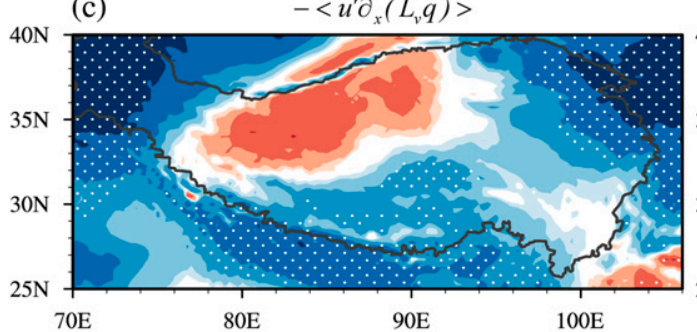

(b)

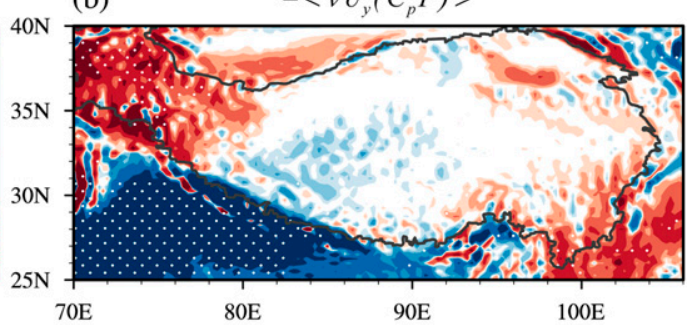

(d)

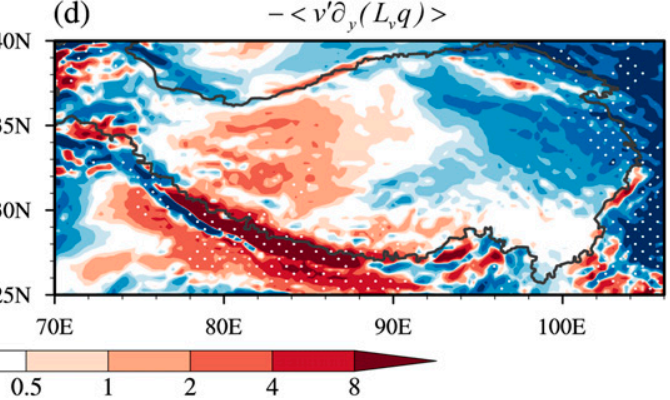

FIG. 8. Spatial distributions of the decomposition of the horizontal advection of climatological moist enthalpy by anomalous winds terms $\left[-\left\langle u^{\prime} \partial_{x} \overline{\left(C_{p} T+L_{v} q\right)}\right\rangle\right.$ and $\left.-\left\langle v^{\prime} \partial_{y} \overline{\left(C_{p} T+L_{v} q\right)}\right\rangle\right]$ : (a) $-\left\langle u^{\prime} \partial_{x} \overline{\left(C_{p} T\right)}\right\rangle$, (b) $-\left\langle v^{\prime} \partial_{y} \overline{\left(C_{p} T\right)}\right\rangle$, (c) $-\left\langle u^{\prime} \partial_{x} \overline{\left(L_{v} q\right)}\right\rangle$, and (d) $-\left\langle v^{\prime} \partial_{y} \overline{\left(L_{v} q\right)}\right\rangle$ (unit: $\mathrm{W} \mathrm{m}^{-1}$ ). Each term is regressed against the summer Niño-3.4 index. The dots denote values exceeding the $95 \%$ confidence level. The black terrain line is the 2000 -m elevation contour. 
(a) $-u^{\prime} \partial_{x} \overline{\left(L_{v} q\right)}$

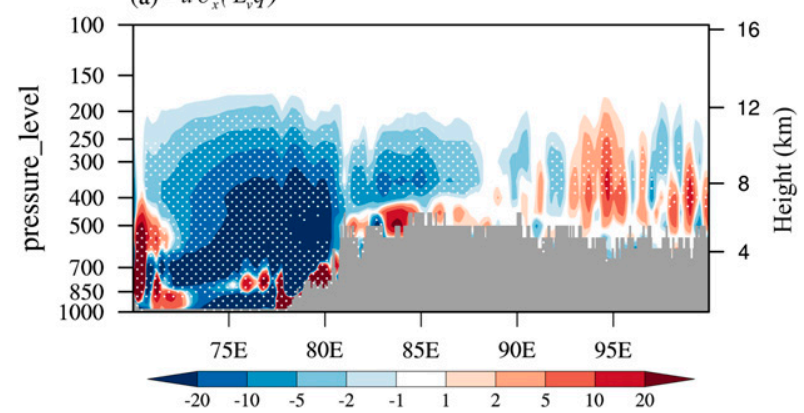

(b) $\bar{q} \&$ Winds@350hPa

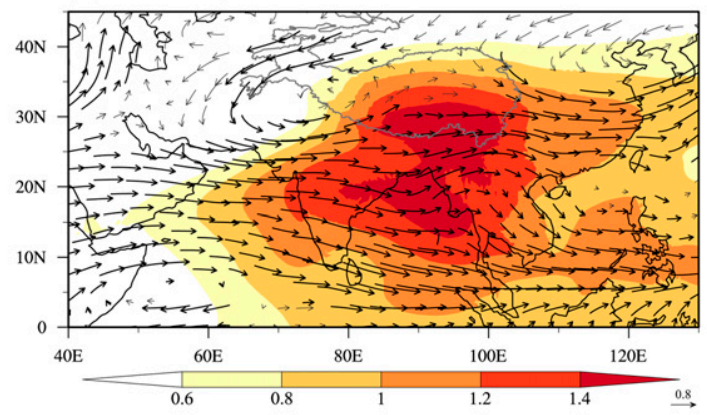

(c) Pr,Winds@350hPa

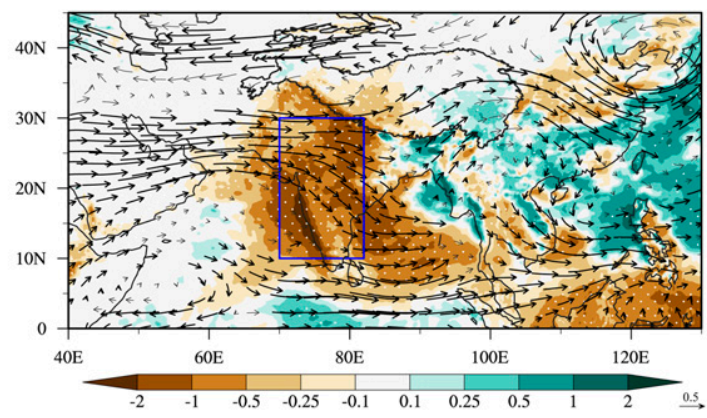

FIG. 9. (a) The longitude-height cross section of the regressions of $-u^{\prime} \partial_{x} \overline{\left(L_{v} q\right)}$ (shaded; unit: $10^{-4} \mathrm{~W} \mathrm{~m}^{-1}$ ) onto the summer Niño3.4 index along $30^{\circ} \mathrm{N}$. The topography is shown as the gray shaded area. (b) The 350-hPa climatological mean summer specific humidity (shaded; unit: $\mathrm{g} \mathrm{kg}^{-1}$ ) and the $350-\mathrm{hPa}$ winds anomalies regressed against the summer Niño-3.4 index (vectors; unit: $\mathrm{m} \mathrm{s}^{-1}$ ). (c) Precipitation (shaded; unit: $\mathrm{mm} \mathrm{day}^{-1}$ ) and $350-\mathrm{hPa}$ winds anomalies (vectors; unit: $\mathrm{ms}^{-1}$ ) regressed against the negative area-averaged precipitation anomalies over the Indian subcontinent (blue box; $10^{\circ}-30^{\circ} \mathrm{N}, 70^{\circ}-82^{\circ} \mathrm{E}$ ). The dots in (a) and (c) denote values exceeding the $90 \%$ confidence level. The thick vectors in (b) and (c) denote values exceeding the $90 \%$ confidence level. The gray terrain line in (b) and (c) is the 2000-m elevation contour.

at $350 \mathrm{hPa}$ are regressed onto the area-averaged precipitation anomalies over the Indian subcontinent $\left(10^{\circ}-30^{\circ} \mathrm{N}, 70^{\circ}-82^{\circ} \mathrm{E}\right)$ (Fig. 9c). There are two equivalent barotropic cyclonic anomalies associated with the negative ISM precipitation occurring over the west of the TP and northeast China, consistent with the circulation anomalies associated with ENSO (Figs. 9b,c). These results suggest that the ISM precipitation anomalies play a role of intermediate bridge in the teleconnection between ENSO and TP summer rainfall. However, it is also evident that the ENSO-related westerly anomalies over the SWTP and the Indian subcontinent are partly caused by the ISM precipitation (Figs. 9b,c), implying that there are other contributed processes.

In summer, the entire TP is controlled by the South Asian high $(\mathrm{SAH})$, which is a large semi-permanent anticyclonic system located at the upper troposphere and lower stratosphere (Wei et al. 2013, 2017; Xue and Chen 2019). The SAH at $350 \mathrm{hPa}$ is weaker than that at $200 \mathrm{hPa}$, but it still has a warmcore high center located near $25^{\circ}-30^{\circ} \mathrm{N}$ (Fig. 10b). The Asian jet streams exist in the northern edge of the $\mathrm{SAH}$ and are centered on $40^{\circ} \mathrm{N}$, while tropical easterlies are dominant to the south of the TP (Fig. 10a). During El Niño's developing summer, there are remarkable upper-tropospheric westerly anomalies over the south of the TP and the tropical north Indian Ocean, accompanied by the negative (positive) potential temperature anomalies over subtropical Eurasia (the tropical Indian Ocean) (Figs. 10c,d), consistent with thermal wind balance (Arkin 1982). Meanwhile, the spatial patterns of the 350-hPa geopotential anomalies are highly consistent with those of the potential temperature anomalies, in which spatial distributions suggest a southward shift of the SAH (Fig. 10d). The meridional shift of the SAH, and therefore the meridional shift of Asian jet stream (Son et al. 2019), contributes to the formation of the westerly anomalies over the SWTP. Therefore, the variances of the upper-tropospheric potential temperature over the tropical north Indian Ocean to the subtropical Eurasia and associated meridional displacements of SAH during El Niño's developing summer are also important for the upper-level zonal flows over the SWTP.

The meridional displacements of SAH caused by the latent heat release from Indian summer monsoon rainfall are noted in Wei et al. (2015). The tropospheric cooling over subtropical Eurasia and the anomalous cyclone to the west of TP are closely linked with the negative ISM precipitation anomalies, while the relationship between the tropical tropospheric warming over the Indian Ocean and ISM precipitation is not significant (Figs. 10e,f). The tropical tropospheric warmings directly forced by ENSO are also key to the formation of the upper-level zonal flows over the SWTP. As noted in previous studies (Yulaeva and Wallace 1994; Chiang and Sobel 2002; Zhou and Zhang 2011), during El Niño's developing summer, the tropical tropospheric warmings over the Indian Ocean arise as a Kelvin wave response to the enhanced convection in the tropical central to eastern Pacific (Figs. 11a,b). As a result, the positive geopotential anomalies are induced over the tropical Indian Ocean, and thus the westerly anomalies prevail from the equator to the subtropical Eurasia regions.

In summary, the anomalous descending motions over the SWTP are primarily caused by the anomalous zonal dry air (low moist enthalpy) advection, which occurs most conspicuously at $350 \mathrm{hPa}$. The anomalous $350-\mathrm{hPa}$ zonal flows over the SWTP are associated with two processes. The first is related to the upper-level cyclonic anomalies over the west of the TP stimulated by the suppressed Indian summer monsoon precipitation. The second is through the meridional shift of SAH, which is related to the ENSO-related anomalous ISM diabatic 
(a) Climatological U@350hPa

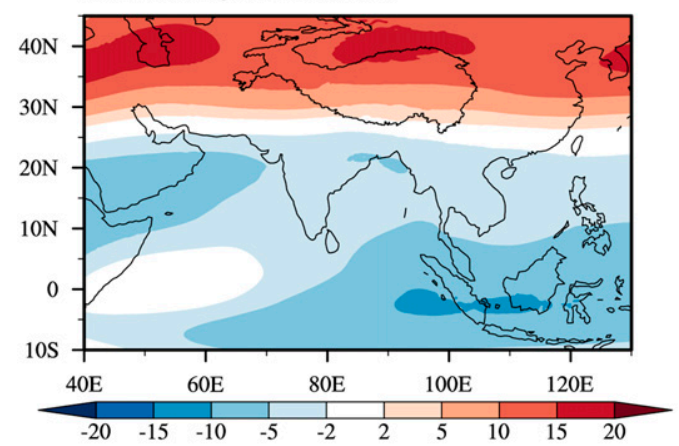

(c) Anomalous U@350hPa

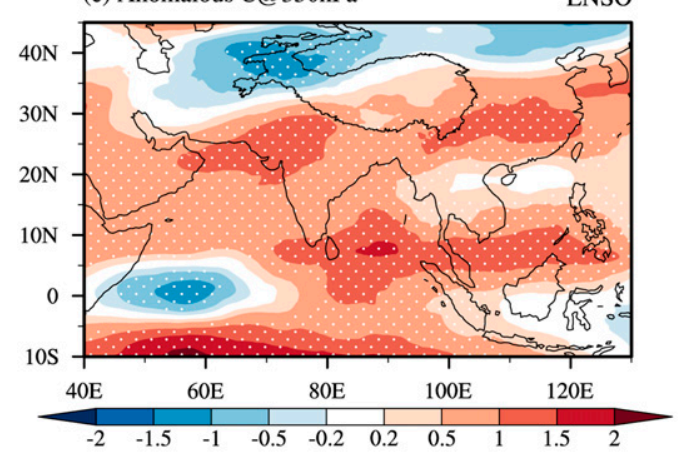

(e) Anomalous U@350hPa

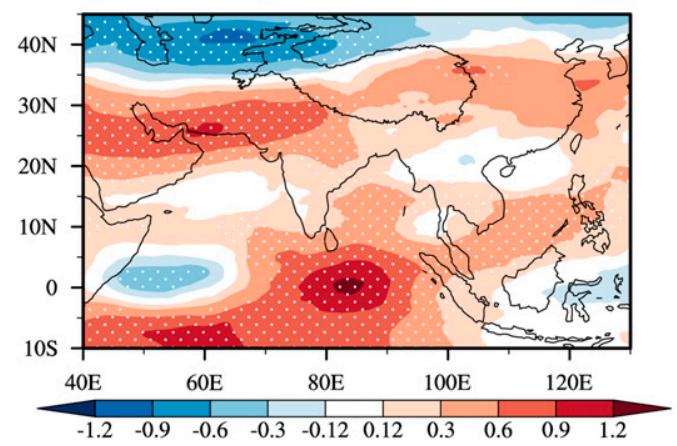

(b) Climatological $\theta @ 350 \mathrm{hPa} \&$ HGT@350hPa

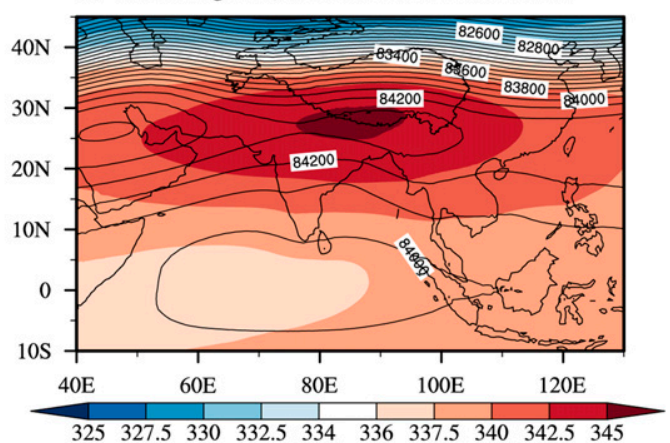

(d) Anomalous $\theta @ 350 \mathrm{hPa} \& \mathrm{HGT} @ 350 \mathrm{hPa}$ ENSO

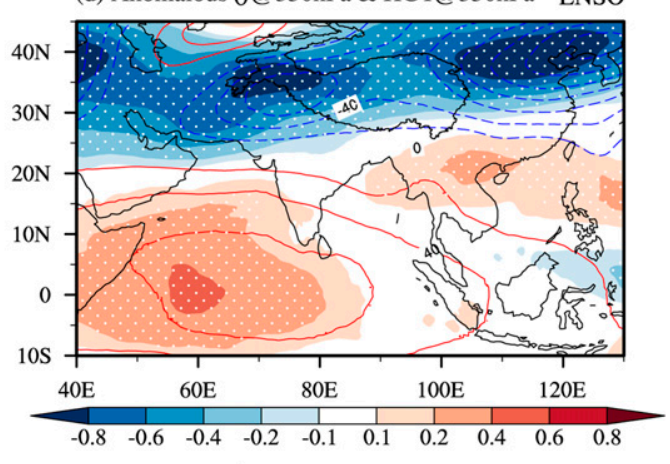

(f) Anomalous $0 @ 350 \mathrm{hPa} \&$ HGT@350hPa ISM

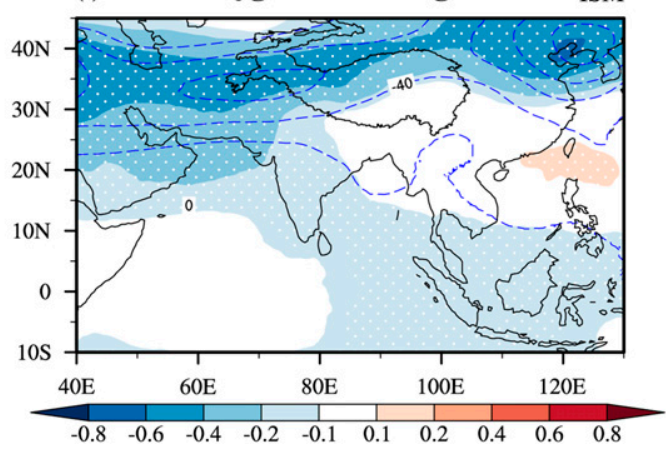

FIG. 10. (a) The climatological JJA-mean 350-hPa zonal wind (shaded; unit: $\mathrm{m} \mathrm{s}^{-1}$ ). (b) The climatological JJAmean 350-hPa potential temperature (shaded; unit: ${ }^{\circ} \mathrm{C}$ ) and geopotential (contours; unit: $\mathrm{m}^{2} \mathrm{~s}^{-2}$ ). Also shown are regressions of (c) the JJA-mean zonal wind anomalies (shaded; unit: $\mathrm{m} \mathrm{s}^{-1}$ ) and (d) anomalous potential temperature anomalies (shaded; unit: ${ }^{\circ} \mathrm{C}$ ) and geopotential anomalies (contours; unit: $\mathrm{m}^{2} \mathrm{~s}^{-2}$ ) onto the summer Niño3.4 index. (e),(f) As in (c) and (d), but for the regressions onto the negative area-averaged precipitation anomalies over the Indian subcontinent (blue box in Fig. $8 \mathrm{c}, 10^{\circ}-30^{\circ} \mathrm{N}, 70^{\circ}-82^{\circ} \mathrm{E}$ ). The dots in (c)-(f) denote values exceeding the $95 \%$ confidence level.

heating and the tropical tropospheric warming induced by the ENSO-induced Kelvin wave.

\section{3) THE THERMODYNAMIC PROCESSES}

The thermodynamic term $\left(-\left\langle\bar{\omega} \partial_{p} q^{\prime}\right\rangle\right)$ is caused by the negative climatological advection of the anomalous vertical moisture (Seager et al. 2010), which value is mainly controlled by the anomalous moist transport, and thus plays a role in thermodynamic processes. To examine the anomalous moisture transport over TP associated with ENSO in summer, we computed the atmospheric precipitable water vapor $(\mathrm{PW})$ and the vertically integrated moisture flux $(Q)$, which are shown in Fig. 12. For the climatological mean, the water vapor imports into the TP through the southern and western boundaries from the Arabian Sea, the midlatitudes, the Bay of Bengal, and the South China Sea (Fig. 12a), which is consistent with previous studies (Simmonds et al. 1999; Feng and Zhou 2012). From the perspective of moisture anomalies, the PW over the SWTP significantly reduces, accompanied by the weakened moisture imports from the western and southern boundary of the SWTP (Fig. 12b). The pattern of the anomalous moisture transports is similar to the low-level atmospheric circulations (Fig. 4d), with 
(a) SSTA, TT

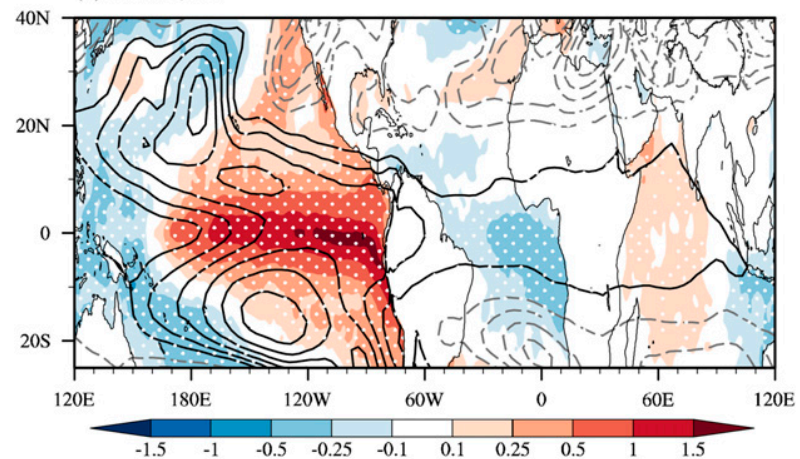

(b) Winds@350hPa, HGT@350hPa

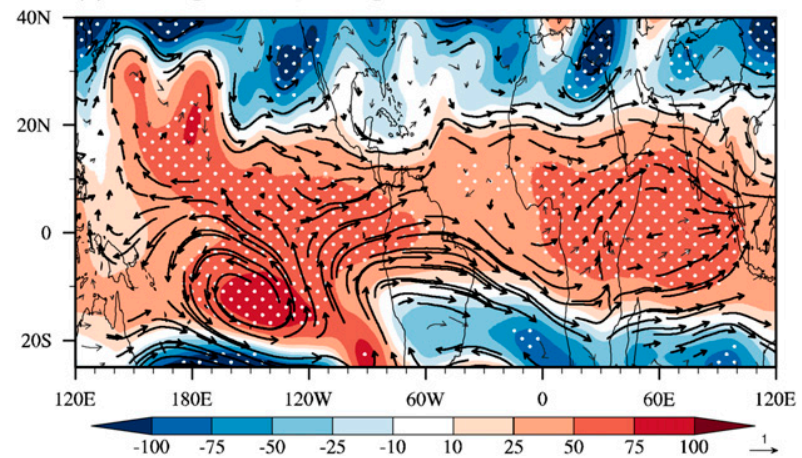

FIG. 11. Regressions of the summer (a) SSTA (shaded; unit: ${ }^{\circ} \mathrm{C}$ ) and tropospheric temperature (TT) anomalies [contours; unit: ${ }^{\circ} \mathrm{C}$; interval value: $0.1^{\circ} \mathrm{C}$; vertical average from 850 to $200 \mathrm{hPa}$; the positive (negative) values are shown in solid (dashed) lines; zero contour is not shown], and (b) 350-hPa winds anomalies (vectors; unit: $\mathrm{m} \mathrm{s}^{-1}$ ) and 350-hPa geopotential anomalies (shaded; unit: $\mathrm{m}^{2} \mathrm{~s}^{-2}$ ) onto the summer Niño-3.4 index. The dots in (a) and (b) denote values exceeding the $95 \%$ confidence level. The thick vectors in (b) denote values exceeding the $90 \%$ confidence level.

two anomalous cyclonic circulations located at the Bay of Bengal and the South China Sea. The results indicate the strengthened India-Burma and western North Pacific monsoon trough. The northwesterly anomalies to the northwestern flank of the anomalous cyclones weaken the eastward and southward transport of water vapor and thus reduce the PW over the SWTP (Fig. 12b).

What factors are responsible for the strengthened monsoon trough during El Niño developing summer? According to the Gill model, the tropical atmospheric circulations anomalies can be forced by the anomalous specified diabatic heating (Gill 1980). Hence, the strengthened IndiaBurma and western North Pacific monsoon trough can be seen as passive responses to the enhanced convective activities over the Bay of Bengal and the South China Sea (Fig. 4b). Two important processes are suggested to interpret the enhanced convective activities over these regions. First, during El Niño's developing summer, the Walker circulations over the tropical Pacific are weakened and eastward shifted (Wang 2002). As a result, the tropical eastern Indian
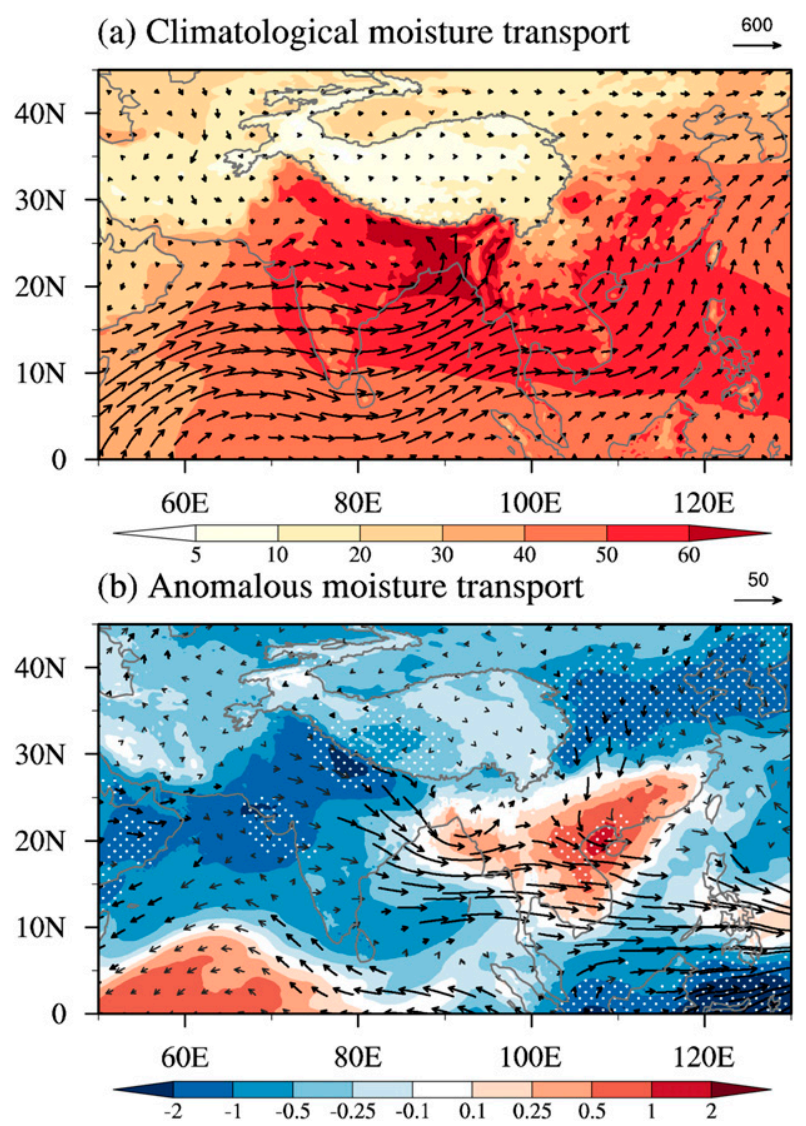

FIG. 12. (a) The climatological JJA-mean PW (shaded; unit: $\mathrm{kg} \mathrm{m}^{-2}$ ) and $Q$ (vectors; unit: $\mathrm{kg} \mathrm{m} \mathrm{s}^{-1}$ ). (b) As in (a), but for the regressions of the anomalous $\mathrm{PW}$ and $Q$ onto the summer Niño-3.4 index. The dots in (b) denote values exceeding the $95 \%$ confidence level. The thick vectors in (b) denote values exceeding the $90 \%$ confidence level. The gray terrain line is the 2000-m elevation contour.

Ocean and the Maritime Continent are covered by the anomalous descending motions, and thus induce the local negative precipitation anomalies, which drive two anomalous anticyclones over both sides of the equator in the tropical Indian Ocean (Fig. 4b). The anomalous anticyclones over the north tropical Indian Ocean make more water vapor transport to the north of the Bay of Bengal and the South China Sea (Fig. 12b), contributing to the increased precipitation. Second, the local Hadley circulations are weakened, with anomalous updraft located at the Bay of Bengal and the South China Sea also contributing to the enhanced convections (Jiang et al. 2016).

\section{Conclusions}

In this study, we use three different rainfall datasets, including APHRODITE, GPCP, and ERA5, to analyze the mechanisms of how developing ENSO events influence the TP precipitation. We have found that the three rainfall datasets show similar anomalous rainfall patterns 

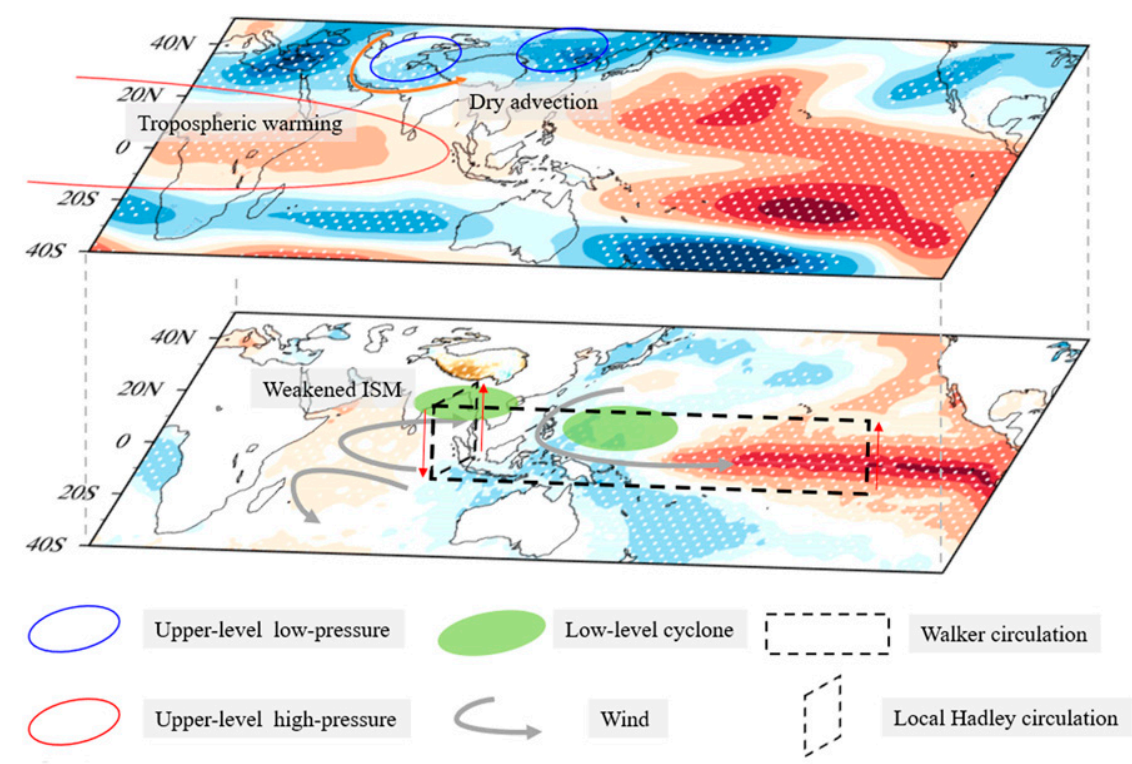

FIG. 13. Schematic of the mechanisms responsible for the influence of developing ENSO on the southwest TP summer rainfall. Both the suppressed vertical motion and the deficit of moisture are conducive to the reduction of SWTP rainfall associated with El Niño. During El Niño developing summer, the El Niño-related negative summer ISM precipitation anomalies induce an upper-level anomalous cyclone to the west of the TP, and the southwesterly anomalies to its southeastern flank contribute to the anomalous zonal dry air (low moist enthalpy) advection into the SWTP. The tropospheric cooling over the subtropical Eurasia associated with the summer ISM precipitation anomalies and the tropical tropospheric warming related to the Kelvin wave response to ENSO's direct forcing leads to the southward displacements of SAH, which also contributes to the anomalous zonal dry advection over the SWTP. The anomalous zonal dry advection plays an essential role in driving descending-motion anomalies and thus negative precipitation anomalies over SWTP by modulating the MSE balance in the atmospheric columns. In addition, the IndiaBurma monsoon trough is strengthened through the "atmospheric bridge," which prevents the water vapor from advecting into the SWTP, which also contributes to the deficit of precipitation.

of the first and second EOF modes, which account for $21.05 \%$ (16.22\%), 35.05\% (16.25\%), and 34.84\% (13.26\%) of the total variance for APHRODITE, GPCP, and ERA5, respectively. The EOF1 is characterized by a dipolar pattern, with rainfall decreasing about $0.2 \mathrm{~mm}$ day $^{-1}$ over the southwest TP and increasing about $0.5-1 \mathrm{~mm}$ day $^{-1}$ over the southeast TP. For the EOF2, the most significant anomalous center is located at the SWTP, with a magnitude of $0.5-1 \mathrm{~mm} \mathrm{day}^{-1}$. The EOF1 (EOF2) is associated with the SNAO (the developing ENSO), respectively. We focus on the formation mechanism of the ENSOrelated EOF2. The schematic of the mechanisms responsible for the influence of developing ENSO on the southwest TP summer rainfall is given in Fig. 13.

The atmospheric moisture budget shows that both the suppressed vertical motion and the deficit of moisture conduce to the reduction of SWTP rainfall anomalies associated with the developing El Niño, with the contribution from the former being 4 times larger than that from the latter. The MSE analyses indicate that the anomalous horizontal moist enthalpy advection is responsible for the anomalous descending motions over the SWTP, and the anomalous zonal dry air (low moist enthalpy) advection has the largest contributions. The climatological summer mean atmospheric specific humidity gradually increases from northwest to southeast over the TP. The anomalous zonal dry air advection over the SWTP is caused by the following two processes: 1) The ENSO-related negative ISM summer precipitation anomalies stimulate a upperlevel anomalous cyclone to the west of the TP, and the southwesterly anomalies to its southeastern flank contribute to the anomalous zonal dry air (low moist enthalpy) advection. 2) The tropospheric cooling over subtropical Eurasia associated with the ISM summer precipitation anomalies and the tropical tropospheric warming related to the Kelvin wave induced by ENSO's direct forcing lead to the southward displacement of SAH, which also has contribution to the anomalous zonal dry advection over the SWTP. For the thermodynamic processes, the India-Burma monsoon trough is strengthened during El Niño developing summer, which prevents the water vapor from transporting into the SWTP, also contributing to the deficit of precipitation.

Our results reveal that the developing phase of ENSO has significant impacts on the summer TP rainfall, and the SWTP is more sensitive to ENSO forcing. A previous study has 
revealed that the summer rainfall over the southwestern TP has a close relationship with the that over central-eastern India, and proposed the "up-and-over" moist transport mechanism to interpret this relationship (Dong et al. 2016). This up-and-over mechanism emphasized that increased horizontal advection of moisture $\left(-\left\langle u \partial_{x} q\right\rangle^{\prime}\right.$ and $\left.-\left\langle v \partial_{y} q\right\rangle^{\prime}\right)$ enhances precipitation over southwestern TP from the perspective of the moisture budget. In contrast, our detailed moisture budget diagnosis indicates that the precipitation anomalies over the SWTP are mainly caused by the anomalous vertical advection of moisture $\left(-\left\langle\omega^{\prime} \partial_{p} \bar{q}\right\rangle\right)$, while the zonal advection of moisture $\left(-\left\langle u \partial_{x} q\right\rangle^{\prime}\right)$ plays a secondary role, with a contribution about $1 / 3$ of $-\left\langle\omega^{\prime} \partial_{p} \bar{q}\right\rangle$. The decreased vertical advection of moisture is attributed to the weakened vertical motion, which is driven by $-\left\langle u^{\prime} \partial_{x} \overline{\left(L_{v} q\right)}\right\rangle$ according to the MSE budget analysis. The differences in the key physical processes may partly be associated with the differences in the target areas between Dong et al. (2016) and this study. The area focused on in their study is smaller than ours and more confined to the southwest boundary of TP.

The ENSO-related precipitation over the TP plays an important role in the modulation of the hydroclimate of the TP. For instance, dramatic lake shrinkages that occurred on the central TP during the developing summers of the 1997/98 and 2015/16 El Niño events have been found recently (Lei et al. 2019; Zhang et al. 2020). Our results suggest that about $38.6 \%$ of the total variance of SWTP summer rainfall variability is contributed by the developing phase of ENSO. For the 1997/98 $(2015 / 16)$ El Niño episode, the SWTP summer rainfall declined by $-0.835(-0.569) \mathrm{mm} \mathrm{day}^{-1}$ or $-17.5 \%(-11.9 \%)$ of climatology, respectively. Through the physical processes revealed in this study, the developing El Niño could explain $39.1 \%(50.8 \%)$ of the rainfall decrease during the 1997 (2015) summer according to the linear statistical relationship, and thus cause significant lake water deficit. An in-depth understanding of the complicated air-sea interaction associated with ENSO is therefore both crucial and urgent for the Third Pole region, and will help us to reduce the socioeconomic impact in the surrounding regions of TP caused by the climate variability and give reliable operational predictions.

Acknowledgments. The study is supported by the Chinese Academy of Sciences under Grant XDA20060102 and the National Natural Science Foundation of China under Grants 41988101 and 41675089 and the Second Tibetan Plateau Scientific Expedition and Research (STEP) program (Grant 2019QZKK0102).

\section{REFERENCES}

Adler, R. F., and Coauthors, 2003: The version 2 Global Precipitation Climatology Project (GPCP) monthly precipitation analysis (1979present). J. Hydrometeor., 4, 1147-1167, https://doi.org/10.1175/ 1525-7541(2003)004<1147:TVGPCP $>2.0 . \mathrm{CO} ; 2$.

Ansell, T., and R. Allan, 2006: A new globally complete monthly historical gridded mean sea level pressure dataset (HadSLP2): 18502004. J. Climate, 19, 5816-5842, https://doi.org/10.1175/JCLI3937.1.

Arkin, P. A., 1982: The relationship between interannual variability in the $200 \mathrm{mb}$ tropical wind field and the Southern Oscillation. Mon. Wea. Rev., 110, 1393-1404, https://doi.org/ 10.1175/1520-0493(1982)110<1393:TRBIVI >2.0.CO;2.
Back, L. E., and C. S. Bretherton, 2006: Geographic variability in the export of moist static energy and vertical motion profiles in the tropical Pacific. Geophys. Res. Lett., 33, L17810, https:// doi.org/10.1029/2006GL026672.

Chen, X., and Q. You, 2017: Effect of Indian Ocean SST on Tibetan Plateau precipitation in the early rainy season. J. Climate, 30, 8973-8985, https://doi.org/10.1175/JCLI-D-16-0814.1.

Cherchi, A., and A. Navarra, 2012: Influence of ENSO and of the Indian Ocean Dipole on the Indian summer monsoon variability. Climate Dyn., 41, 81-103, https://doi.org/10.1007/ s00382-012-1602-y.

Chiang, J. C. H., and A. H. Sobel, 2002: Tropical tropospheric temperature variations caused by ENSO and their influence on the remote tropical climate. J. Climate, 15, 2616-2631, https://doi.org/10.1175/ 1520-0442(2002)015<2616:TTTVCB >2.0.CO;2.

Ding, Q. H., and B. Wang, 2005: Circumglobal teleconnection in the Northern Hemisphere summer. J. Climate, 18, 3483-3505, https://doi.org/10.1175/JCLI3473.1.

Dong, W., and Coauthors, 2016: Summer rainfall over the southwestern Tibetan Plateau controlled by deep convection over the Indian subcontinent. Nat. Commun., 7, 10925, https:// doi.org/10.1038/ncomms10925.

Du, Y., S.-P. Xie, G. Huang, and K. Hu, 2009: Role of air-sea interaction in the long persistence of El Niño-induced north Indian Ocean warming. J. Climate, 22, 2023-2038, https:// doi.org/10.1175/2008JCLI2590.1.

Duan, A., and G. Wu, 2008: Weakening trend in the atmospheric heat source over the Tibetan Plateau during recent decades. Part I: Observations. J. Climate, 21, 3149-3164, https://doi.org/ 10.1175/2007JCLI1912.1.

Duchon, C. E., 1979: Lanczos filtering in one and two dimensions. J. Appl. Meteor., 18, 1016-1022, https://doi.org/10.1175/15200450(1979)018<1016:LFIOAT>2.0.CO;2.

Feng, L., and T. Zhou, 2012: Water vapor transport for summer precipitation over the Tibetan Plateau: Multidata set analysis. J. Geophys. Res., 117, D20114, https://doi.org/10.1029/2011JD017012.

Folland, C. K., J. Knight, H. W. Linderholm, D. Fereday, S. Ineson, and J. W. Hurrell, 2009: The summer North Atlantic Oscillation: Past, present, and future. J. Climate, 22, 10821103, https://doi.org/10.1175/2008JCLI2459.1.

Gao, J., Y. He, V. Masson-Delmotte, and T. Yao, 2018: ENSO effects on annual variations of summer precipitation stable isotopes in Lhasa, southern Tibetan Plateau. J. Climate, 31, 1173-1182, https://doi.org/10.1175/JCLI-D-16-0868.1.

Gao, Y., H. Wang, and S. Li, 2013: Influences of the Atlantic Ocean on the summer precipitation of the southeastern Tibetan Plateau. J. Geophys. Res. Atmos., 118, 3534-3544, https:// doi.org/10.1002/jgrd.50290.

Gill, A. E., 1980: Some simple solutions for heat-induced tropical circulation. Quart. J. Roy. Meteor. Soc., 106, 447-462, https:// doi.org/10.1002/qj.49710644905.

He, C., Z. Wang, T. Zhou, and T. Li, 2019: Enhanced latent heating over the Tibetan Plateau as a key to the enhanced East Asian summer monsoon circulation under a warming climate. J. Climate, 32, 3373-3388, https://doi.org/10.1175/ JCLI-D-18-0427.1.

Hersbach, H., and D. Dee, 2016: ERA5 reanalysis is in production. ECMWF Newsletter, No. 147, ECMWF, Reading, United Kingdom, 7, http://www.ecmwf.int/sites/default/files/elibrary/ 2016/16299-newsletter-no147-spring-2016.pdf.

Hu, J., and A. Duan, 2015: Relative contributions of the Tibetan Plateau thermal forcing and the Indian Ocean Sea surface temperature basin mode to the interannual variability of the 
East Asian summer monsoon. Climate Dyn., 45, 2697-2711, https://doi.org/10.1007/s00382-015-2503-7.

Immerzeel, W. W., L. P. van Beek, and M. F. Bierkens, 2010: Climate change will affect the Asian water towers. Science, 328, 1382-1385, https://doi.org/10.1126/science.1183188.

Jiang, X., and M. Ting, 2017: A dipole pattern of summertime rainfall across the Indian subcontinent and the Tibetan Plateau. J. Climate, 30, 9607-9620, https://doi.org/10.1175/ JCLI-D-16-0914.1.

—, Y. Li, S. Yang, K. Yang, and J. Chen, 2016: Interannual variation of summer atmospheric heat source over the Tibetan Plateau and the role of convection around the western maritime continent. J. Climate, 29, 121-138, https://doi.org/10.1175/ JCLI-D-15-0181.1.

Jin, R., Z. Wu, and P. Zhang, 2017: Tibetan Plateau capacitor effect during the summer preceding ENSO: From the Yellow River climate perspective. Climate Dyn., 51, 57-71, https://doi.org/ 10.1007/s00382-017-3906-4.

Kim, J.-Y., K.-H. Seo, J.-H. Son, and K.-J. Ha, 2017: Development of statistical prediction models for Changma precipitation: An ensemble approach. Asia-Pac. J. Atmos. Sci., 53, 207-216, https://doi.org/10.1007/s13143-017-0027-2.

Klein, S. A., B. J. Soden, and N.-C. Lau, 1999: Remote sea surface temperature variations during ENSO: Evidence for a tropical atmospheric bridge. J. Climate, 12, 917-932, https://doi.org/ 10.1175/1520-0442(1999)012<0917:RSSTVD>2.0.CO;2.

Knight, J., C. K. Folland, H. W. Linderholm, D. Fereday, S. Ineson, and J. W. Hurrell, 2009: The summer North Atlantic Oscillation: Past, present, and future. J. Climate, 22, 10821103, https://doi.org/10.1175/2008JCLI2459.1.

Krishnan, R., and M. Sugi, 2001: Baiu rainfall variability and associated monsoon teleconnections. J. Meteor. Soc. Japan, 79, 851-860, https://doi.org/10.2151/jmsj.79.851.

Kumar, K. K., 1999: On the weakening relationship between the Indian monsoon and ENSO. Science, 284, 2156-2159, https:// doi.org/10.1126/science.284.5423.2156.

Lei, Y., and Coauthors, 2019: Extreme lake level changes on the Tibetan Plateau associated with the 2015/2016 El Niño. Geophys. Res. Lett., 46, 5889-5898, https://doi.org/10.1029/ 2019GL081946.

Li, T., B. Wang, B. Wu, T. J. Zhou, C. P. Chang, and R. H. Zhang, 2017: Theories on formation of an anomalous anticyclone in western North Pacific during El Niño: A review. J. Meteor. Res., 31, 987-1006, https://doi.org/10.1007/s13351-017-7147-6.

Liu, H., K. Duan, M. Li, P. Shi, J. Yang, X. Zhang, and J. Sun, 2015: Impact of the North Atlantic Oscillation on the dipole oscillation of summer precipitation over the central and eastern Tibetan Plateau. Int. J. Climatol., 35, 4539-4546, https:// doi.org/10.1002/joc.4304.

Liu, X., and Z.-Y. Yin, 2001: Spatial and temporal variation of summer precipitation over the eastern Tibetan Plateau and the North Atlantic Oscillation. J. Climate, 14, 2896-2909, https://doi.org/10.1175/1520-0442(2001)014<2896:SATVOS> 2.0.CO;2.

Moron, V., and I. Gouirand, 2003: Seasonal modulation of the El Niño-southern oscillation relationship with sea level pressure anomalies over the North Atlantic in October-March 1873 1996. Int. J. Climatol., 23, 143-155, https://doi.org/10.1002/ joc. 868 .

Neelin, J. D., 2007: Moist dynamics of tropical convection zones in monsoons, teleconnections, and global warming. The Global Circulation of the Atmosphere, T. Schneider and A. Sobel, Eds., Princeton University Press, 267-301.
— , and I. M. Held, 1987: Modeling tropical convergence based on the moist static energy budget. Mon. Wea. Rev., 115, 3-12, https://doi.org/10.1175/1520-0493(1987)115<0003: MTCBOT $>2.0 . \mathrm{CO} ; 2$.

North, G. R., T. L. Bell, R. F. Cahalan, and F. J. Moeng, 1982: Sampling errors in the estimation of empirical orthogonal functions. Mon. Wea. Rev., 110, 699-706, https://doi.org/ 10.1175/1520-0493(1982)110<0699:SEITEO > 2.0.CO;2.

Park, H. L., K. H. Seo, and J. H. Son, 2015: Development of a dynamics-based statistical prediction model for the changma onset. J. Climate, 28, 6647-6666, https://doi.org/10.1175/JCLID-14-00502.1.

Pubu, Z. M., S. W. Zhou, and Y. H. Fu, 2002: Reflection from the ENSO event on precipitation during the summer of Tibet (in Chinese). Tibet. Sci. Technol., 2, 41-47.

Rayner, N. A., D. E. Parker, E. B. Horton, C. K. Folland, L. V. Alexander, D. P. Rowell, E. C. Kent, and A. Kaplan, 2003: Global analyses of sea surface temperature, sea ice, and night marine air temperature since the late nineteenth century. J. Geophys. Res., 108, 4407, https://doi.org/10.1029/ 2002JD002670.

Ren, Q., C. Zhou, J. He, S. Cen, and M. Deng, 2017: Impact of preceding Indian Ocean sea surface temperature anomaly on water vapor content over the Tibetan Plateau moist pool in summer and its possible reason (in Chinese). Chin. J. Atmos. Sci., 41, 648-658.

Seager, R., N. Naik, and G. A. Vecchi, 2010: Thermodynamic and dynamic mechanisms for large-scale changes in the hydrological cycle in response to global warming. J. Climate, $\mathbf{2 3}$, 4651-4668, https://doi.org/10.1175/2010JCLI3655.1.

_,- , and L. Vogel, 2012: Does global warming cause intensified interannual hydroclimate variability? J. Climate, $\mathbf{2 5}$, 3355-3372, https://doi.org/10.1175/JCLI-D-11-00363.1.

Simmonds, I., D. Bi, and P. Hope, 1999: Atmospheric water vapor flux and its association with rainfall over China in summer. J. Climate, 12, 1353-1367, https://doi.org/10.1175/1520-0442(1999) 012<1353:AWVFAI $>2.0$. CO 2 .

Son, J.-H., K.-H. Seo, and B. Wang, 2019: Dynamical control of the Tibetan Plateau on the East Asian summer monsoon. Geophys. Res. Lett., 46, 7672-7679, https://doi.org/10.1029/ 2019 GL083104.

,-- , and - 2020: How does the Tibetan Plateau dynamically affect downstream monsoon precipitation? Geophys. Res. Lett., 47, e2020GL090543, https://doi.org/ 10.1029/2020GL090543.

Wang, B., R. Wu, and X. Fu, 2000: Pacific-East Asian teleconnection: How does ENSO affect East Asian climate? J. Climate, 13, 1517-1536, https://doi.org/10.1175/15200442(2000)013<1517:PEATHD>2.0.CO;2.

- - - and K. M. Lau, 2001: Interannual variability of the Asian summer monsoon: Contrasts between the Indian and the western North Pacific-East Asian monsoons. J. Climate, 14, 4073-4090, https://doi.org/10.1175/1520-0442(2001)014<4073: IVOTAS $>2.0 . \mathrm{CO} ; 2$.

Wang, C. X., and Z. F. Ma, 2018: Quasi-3-yr cycle of rainy season precipitation in Tibet related to different types of ENSO during 1981-2015. J. Meteor. Res., 32, 181-190, https://doi.org/ 10.1007/s13351-018-7100-3.

Wang, C. Z., 2002: Atmospheric circulation cells associated with the El Niño-Southern Oscillation. J. Climate, 15, 399-419, https://doi.org/10.1175/1520-0442(2002)015<0399:ACCAWT> 2.0. $\mathrm{CO} ; 2$. 
, 2019: Three-ocean interactions and climate variability: A review and perspective. Climate Dyn., 53, 5119-5136, https:// doi.org/10.1007/s00382-019-04930-x.

Wang, H., B. Wang, F. Huang, Q. Ding, and J.-Y. Lee, 2012: Interdecadal change of the boreal summer circumglobal teleconnection (1958-2010). Geophys. Res. Lett., 39, L12704, https://doi.org/10.1029/2012GL052371.

Wang, Z. B., R. Wu, S. Chen, G. Huang, G. Liu, and L. Zhu, 2018: Influence of western Tibetan Plateau summer snow cover on East Asian summer rainfall. J. Geophys. Res. Atmos., 123, 2371-2386, https://doi.org/10.1002/ 2017JD028016.

Wang, Z. Q., A. Duan, S. Yang, and K. Ullah, 2017: Atmospheric moisture budget and its regulation on the variability of summer precipitation over the Tibetan Plateau. J. Geophys. Res. Atmos., 122, 614-630, https://doi.org/10.1002/2016JD025515.

—, S. Yang, N.-C. Lau, and A. Duan, 2018: Teleconnection between summer NAO and East China rainfall variations: A bridge effect of the Tibetan Plateau. J. Climate, 31, 6433-6444, https://doi.org/10.1175/JCLI-D-17-0413.1.

Watanabe, M., 2004: Asian jet waveguide and a downstream extension of the North Atlantic Oscillation. J. Climate, 17, 46744691, https://doi.org/10.1175/JCLI-3228.1.

Wei, W., R. Zhang, M. Wen, X. Rong, and T. Li, 2013: Impact of Indian summer monsoon on the South Asian high and its influence on summer rainfall over China. Climate Dyn., 43, 1257-1269, https://doi.org/10.1007/s00382-013-1938-y.

,,--- , B.-J. Kim, and J.-C. Nam, 2015: Interannual variation of the South Asian high and its relation with Indian and East Asian summer monsoon rainfall. J. Climate, 28, 2623-2634, https://doi.org/10.1175/JCLI-D-14-00454.1.

$-,-\longrightarrow, \ldots$, and S. Yang, 2017: Relationship between the Asian westerly jet stream and summer rainfall over central Asia and North China: Roles of the Indian monsoon and the South Asian high. J. Climate, 30, 537-552, https://doi.org/ 10.1175/JCLI-D-15-0814.1.

Wu, B., T. Zhou, and T. Li, 2009: Seasonally evolving dominant interannual variability modes of East Asian climate. J. Climate, 22, 2992-3005, https://doi.org/10.1175/ 2008JCLI2710.1.

— , T. Li, and T. Zhou, 2010: Relative contributions of the Indian Ocean and local SST anomalies to the maintenance of the western North Pacific anomalous anticyclone during the El Niño decaying summer. J. Climate, 23, 2974-2986, https:// doi.org/10.1175/2010JCLI3300.1.

— , T. Zhou, and T. Li, 2017a: Atmospheric dynamic and thermodynamic processes driving the western North Pacific anomalous anticyclone during El Niño. Part I: Maintenance mechanisms. J. Climate, 30, 9621-9635, https://doi.org/10.1175/ JCLI-D-16-0489.1.

,-- , and,$- 2017 \mathrm{~b}$ : Atmospheric dynamic and thermodynamic processes driving the western North Pacific anomalous anticyclone during El Niño. Part II: Formation processes. J. Climate, 30, 9637-9650, https://doi.org/10.1175/JCLI-D-160495.1.

Wu, G., and Coauthors, 2007: The influence of mechanical and thermal forcing by the Tibetan Plateau on Asian climate. J. Hydrometeor., 8, 770-789, https://doi.org/10.1175/ JHM609.1.

, Y. Liu, B. He, Q. Bao, A. Duan, and F.-F. Jin, 2012: Thermal controls on the Asian summer monsoon. Sci. Rep., 2, 404, https://doi.org/10.1038/srep00404.
Wu, R. G., Z. Z. Hu, and B. P. Kirtman, 2003: Evolution of ENSOrelated rainfall anomalies in East Asia. J. Climate, 16, 37423758, https://doi.org/10.1175/1520-0442(2003)016<3742: EOERAI $>2.0 . \mathrm{CO} ; 2$.

Wu, Z., B. Wang, J. Li, and F.-F. Jin, 2009: An empirical seasonal prediction model of the East Asian summer monsoon using ENSO and NAO. J. Geophys. Res., 114, D18120, https:// doi.org/10.1029/2009JD011733.

Xie, S.-P., and Coauthors, 2009: Indian Ocean capacitor effect on Indowestern Pacific climate during the summer following El Niño. J. Climate, 22, 730-747, https://doi.org/10.1175/2008JCLI2544.1.

—_, Y. Kosaka, Y. Du, K. Hu, J. S. Chowdary, and G. Huang, 2016: Indo-western Pacific Ocean capacitor and coherent climate anomalies in post-ENSO summer: A review. $A d v$. Atmos. Sci., 33, 411-432, https://doi.org/10.1007/s00376-0155192-6.

Xu, J. J., and J. Lu, 1992: Precipitation over the Qinghai-Xizang Plateau in summer and its association with the Eurasian snow cover (in Chinese). J. Nanjing Inst. Meteor., 15, 517524.

Xu, X., C. Lu, X. Shi, and S. Gao, 2008: World water tower: An atmospheric perspective. Geophys. Res. Lett., 35, L20815, https://doi.org/10.1029/2008GL035867.

Xue, X., and W. Chen, 2019: Distinguishing interannual variations and possible impacted factors for the northern and southern mode of South Asia high. Climate Dyn., 53, 4937-4959, https:// doi.org/10.1007/s00382-019-04837-7.

Yang, M. X., T. D. Yao, Y. Q. He, and L. G. Thompson, 2000: ENSO events recorded in the Guliya ice core. Climatic Change, 47, 401-409, https://doi.org/10.1023/A: 1005696702385.

Yang, X., T. Yao, Deji, H. Zhao, and B. Xu, 2018: Possible ENSO influences on the northwestern Tibetan Plateau revealed by annually resolved ice core records. J. Geophys. Res. Atmos., 123, 3857-3870, https://doi.org/10.1002/2017JD027755.

Yatagai, A., K. Kamiguchi, O. Arakawa, A. Hamada, N. Yasutomi, and A. Kitoh, 2012: APHRODITE: Constructing a long-term daily gridded precipitation dataset for Asia based on a dense network of rain gauges. Bull. Amer. Meteor. Soc., 93, 14011415, https://doi.org/10.1175/BAMS-D-11-00122.1.

Yeh, S. W., and Coauthors, 2018: ENSO atmospheric teleconnections and their response to greenhouse gas forcing. Rev. Geophys., 56, 185-206, https://doi.org/10.1002/2017RG000568.

Yulaeva, E., and J. M. Wallace, 1994: Signature of ENSO in global temperature and precipitation fields derived from the Microwave Sounding Unit. J. Climate, 7, 1719-1736, https://doi.org/10.1175/ 1520-0442(1994)007<1719:TSOEIG>2.0.CO;2.

Zhang, G., and Coauthors, 2020: Response of Tibetan Plateau's lakes to climate changes: Trend, pattern, and mechanisms. Earth-Sci. Rev., 208, 103269, https://doi.org/10.1016/ J.EARSCIREV.2020.103269.

Zhang, L., F. Su, D. Yang, Z. Hao, and K. Tong, 2013: Discharge regime and simulation for the upstream of major rivers over Tibetan Plateau. J. Geophys. Res. Atmos., 118, 8500-8518, https://doi.org/10.1002/jgrd.50665.

Zhang, W., X. Mei, X. Geng, A. G. Turner, and F.-F. Jin, 2019: A nonstationary ENSO-NAO relationship due to AMO modulation. J. Climate, 32, 33-43, https://doi.org/10.1175/JCLI-D18-0365.1.

Zhao, Y., and T. Zhou, 2019: Asian water tower evinced in total column water vapor: A comparison among multiple satellite and reanalysis data sets. Climate Dyn., 54, 231-245, https:// doi.org/10.1007/S00382-019-04999-4. 
_ A. Duan, and G. Wu, 2018: Interannual variability of latespring circulation and diabatic heating over the Tibetan Plateau associated with Indian Ocean forcing. Adv. Atmos. Sci., 35, 927-941, https://doi.org/10.1007/s00376-018-7217-4.

Zhou, C., P. Zhao, and J. Chen, 2019: The interdecadal change of summer water vapor over the Tibetan Plateau and associated mechanisms. J. Climate, 32, 4103-4119, https://doi.org/10.1175/ JCLI-D-18-0364.1.
Zhou, T. J., and R. C. Yu, 2005: Atmospheric water vapor transport associated with typical anomalous summer rainfall patterns in China. J. Geophys. Res., 110, D08104, https://doi.org/10.1029/ 2004JD005413.

_, and J. Zhang, 2011: The vertical structures of atmospheric temperature anomalies associated with two flavors of El Niño simulated by AMIP II models. J. Climate, 24, 1053-1070, https://doi.org/10.1175/2010JCLI3504.1. 